\title{
Bioelectrochemical analysis of thermodynamics of the catalytic cycle and kinetics of the oxidative inactivation of oxygen-tolerant [NiFe]-hydrogenase
}

Keisei So ${ }^{\text {a }}$, Rui Hamamoto ${ }^{\text {a }}$, Ryosuke Takeuchi ${ }^{\text {a }}$, Yuki Kitazumi ${ }^{\text {a }}$, Osamu Shirai ${ }^{\text {a }}$, Ryohei Endo

${ }^{\mathrm{b}}$, Hirofumi Nishihara ${ }^{\mathrm{b}}$, Yoshiki Higuchi ${ }^{\mathrm{c}}$, and Kenji Kano ${ }^{\mathrm{a}, *}$

a Division of Applied Life Sciences, Graduate School of Agriculture, Kyoto University, Sakyo, Kyoto 606-8502, Japan

b Department of Bioresource Science, Collage of Agriculture, Ibaraki University, Ami-machi, Inashiki-gun, Ibaraki 300-0393, Japan

c Department of Life Science, Graduate School of Life Science, University of Hyogo, 3-2-1 Koto, Kamigori-cho, Ako-gun, Hyogo 678-1297, Japan

\begin{abstract}
Membrane-bound [NiFe]-hydrogenase from Hydrogenovibrio marinus (HmMBH) is an $\mathrm{O}_{2}$-tolerant enzyme and allows direct electron transfer (DET)-type bioelectrocatalysis for the $\mathrm{H}_{2}$ oxidation. Very fast interfacial electron transfer occurs between the [NiFe]-active site of $\mathrm{HmMBH}$ and the electrode, and the potential dependence of the steady-state DET-type catalytic current has been analyzed on a thermodynamic model of a two-step one-electron transfer to get a Pourbaix diagram of the catalytic center. A reversible and oxidative inactivation that occurs when the [NiFe]-hydrogenases are suffered from the oxidative stress at high electrode potentials or high solution potentials has been kinetically analyzed for the time-dependence of the steady-state catalytic current as a measure. The kinetic analysis has shown that the rate-determining step of the oxidative inactivation is not electrochemical but chemical process and that the rate of the reductive reactivation is determined by the electrochemical process. The observed catalytic waves, especially the dependence of the waves on the scan rate and the hydrogen concentration, have been well reproduced by simulation with the thermodynamic and kinetic parameters evaluated here.
\end{abstract}


* Correspondence author. Tel: +81-75-753-6392, fax: +81-75-753-6456.

E-mail address: kano.kenji.5z@kyoto-u.ac.jp (K. Kano)

Keywords: membrane-bound [NiFe]-hydrogenase, direct electron transfer-type bioelectrocatalysis, Nernst analysis, oxidative inactivation, digital simulation 


\section{Introduction}

Hydrogenases catalyze the $\mathrm{H}_{2}$ oxidation and $\mathrm{H}_{2}$ evolution [1-3]. There are three main classes of hydrogenases based on their active site metals: [Fe] enzymes with only one iron atom in the active site, $[\mathrm{FeFe}]$ enzymes with two iron atoms in the active site, and [NiFe] enzymes that possess a heterobimetallic active site. Although most of the [Fe] and [FeFe] proteins are known to be extremely $\mathrm{O}_{2}$-sensitive, the $[\mathrm{NiFe}]$ proteins are not only $\mathrm{O}_{2}$-sensitive but $\mathrm{O}_{2}$-resistant or $\mathrm{O}_{2}$-tolerant [1-3]. Generally, the [NiFe]-hydrogenases comprise a large subunit that incorporates the [NiFe]-active site and a small subunit that houses an electron relay chain of [FeS]-clusters, and they are located in the periplasmic space and are often associated with a membrane. In periplasmic space, the hydrogenases may be anchored to the membrane via $b$-type cytochrome that mediates the electron transfer from $\mathrm{H}_{2}$ to the respiratory chain quinone pool [1-3].

Many spectroscopic studies have revealed that the [NiFe]-active site stays in several states such as Ni-SI (active silent state), Ni-R ( $\mathrm{H}_{2}$-reduced state), Ni-C (one-electron-oxidized state of Ni-R), Ni-A (inactive-state with high kinetic barrier for reactivation, also known as “unready” state), and Ni-B (reversible inactive-state with low kinetic barrier for reactivation, also known as "ready" state) [1-3]. As summarized in Scheme 1 , for the $\mathrm{H}_{2}$ oxidation, the $\mathrm{H}_{2}$-binding to the Ni-SI state is the first step and subsequently the catalytic cycle proceeds in the Ni-R, Ni-C and Ni-SI states in turn. In the case of the standard [NiFe]-hydrogenases, however, the Ni-SI state changes to the Ni-A and Ni-B states on the oxidative stress. The Ni-A state seems to be produced by one-electron oxidation of the Ni-SI state, in which a peroxide ligand is considered to be coordinated to the $\mathrm{Ni}$ atom in the bridging position with respect to the Fe(II). However, there has been much debate about oxygenation of sulfurs near the active site in recent literature [4]. The Ni-B state is produced also by one-electron oxidation of the Ni-SI state, in which, in contrast to the Ni-A state, a hydroxide ligand is coordinated to the $\mathrm{Ni}$ atom in the bridging position with respect to the $\mathrm{Fe}(\mathrm{II})$ [1-3]. Among the [NiFe]-hydrogenases, $\mathrm{O}_{2}$-tolerant and membrane-bound hydrogenases from Ralstonia species [5,6], Aquifex aeolicus [7,8], Escherichia coli [9,10] and Hydrogenovibrio marinus [11,12] have been found, and they have the unique property of catalyzing the $\mathrm{H}_{2}$ oxidation in the sustained presence of $\mathrm{O}_{2}$. The $\mathrm{O}_{2}$-tolerant mechanism has been considered due to the presence, close to the active site, of 
a unique [FeS]-cluster (a [4Fe-3S]-cluster coordinated by six Cys residues rather than a [4Fe-4S]-cluster coordinated by four Cys residues as to other [NiFe]-hydrogenases) that transfers two electrons rapidly to the active site when the hydrogenase is attacked by $\mathrm{O}_{2}$ and thus can protect the enzyme against damaging intermediate reduction products of $\mathrm{O}_{2}[6,7,9,11]$. Consequently, the ability is very useful and convenient for us in utilization of the hydrogenases for practical applications.

Bioelectrocatalysis as a coupled reaction of the enzymatic catalytic reaction and the electrode reaction is classified into two types in accordance with the electric connection systems [13-18]. One is the mediated electron transfer (MET)-type, in which artificial redox mediators shuttle electrons between enzymes and electrodes to reduce the kinetic hindrance in the interfacial electron transfer. The other is the direct electron transfer (DET)-type, in which enzymes can directly transfer electrons to or from electrodes. Biofuel cells can be constructed based on bioelectrocatalysis. The recent advances of biofuel cells are summarized by Minteer's group [19]. The device is very secure since it can operate under mild conditions (room temperature, atmospheric pressure and neutral $\mathrm{pH}$ ). Accordingly, it is also possible to be utilized as micro-electronic power devices that can extract energy from biological sources [20-23]. There are limited number of redox enzymes capable of direct communication with electrodes, but some of hydrogenases are known as DET-type enzymes [1,13,18]. This feature enables us to construct $\mathrm{H}_{2}$-oxidating bioanodes for DET-type biofuel cells that are very simple and compact due to minimum components (only enzyme, electrode and electrolyte) [24-27]. For $\mathrm{O}_{2}$ reduction, several multi-copper oxidases (MCOs) such as laccase, bilirubin oxidase, and $\mathrm{Cu}$ efflux oxidase work as DET-type enzymes and are used in $\mathrm{O}_{2}$-reducing biocathodes [28-30]. By utilizing hydrogenases and MCOs, a DET-type $\mathrm{H}_{2} / \mathrm{O}_{2}$ biofuel cell can be constructed. Since the electric power device does not need platinum, it might solve the platinum-depletion-problem concerning $\mathrm{H}_{2} / \mathrm{O}_{2}$ fuel cells. In fact, Lojou's group and Armstrong's group have reported power devices with a power density of $1.5 \mathrm{~mW}$ $\mathrm{cm}^{-2}$ (at $60{ }^{\circ} \mathrm{C}$ with $\mathrm{MBH}$ from A. aeolicus and BOD from B. pumilus) [24] and $1.67 \mathrm{~mW} \mathrm{~cm}^{-2}$ (at $25^{\circ} \mathrm{C}$ with $\mathrm{MBH}$ from E. coli and BOD from M. verrucaria; noting here that the surface area of the cathode is 3 times larger than that of the anode and the power density is calculated on the basis of the surface area of the anode) [25], respectively. 
In addition to the aforementioned redox enzymes (hydrogenases and MCOs), fructose dehydrogenase [31,32] and cellobiose dehydrogenase [33,34] are also known as DET-type enzymes. Catalytic voltammograms on DET-type enzyme-modified electrode tell us the characteristics of the enzymes [18]. Most of DET-type enzymes produce catalytic voltammograms with quasi-reversible or irreversible characteristics of the electron transfer between the enzymes and electrode. Unfavorable orientation of the modified enzyme leads to high overpotentials, and the steady-state catalytic current in voltammograms continues to increase linearly with the potential (called as “residual slope”) after the sigmoidal increase [35]. This phenomenon has been theoretically explained by Léger et al., in which they have considered effects of a dispersion on the interfacial electron transfer rate by assuming the random disorder of the distance between the electrode and the active site [35]. In this model (called dispersion model), they have taken into account the distribution of the distance from the active site of the enzyme to the electrode. Subsequently, the interfacial electron transfer rate constant is expressed based on a relation in which the electron transfer rate constant decreases exponentially with the tunneling distance between the electrode and the active site of the enzyme [36]. Finally, quasi-reversible or irreversible catalytic voltammograms can be interpreted with several factors concerning the redox potential, the standard electron transfer rate constant, and the enzyme orientation.

Hydrogenases often give sigmoidal steady-state catalytic voltammograms with the residual slope. Léger et al. analyzed voltammograms of the catalytic $\mathrm{H}_{2}$ oxidation and $\mathrm{H}_{2}$ evolution with reversible characteristics obtained at [NiFe]-hydrogenase (from A. vinosum)-adsorbed electrode on a model of the two-step one-electron transfer (corresponding to the redox reaction of the Ni-SI, $\mathrm{Ni}-\mathrm{R}$ and Ni-C states) by using the aforementioned dispersion model [35,37]. To get an acceptable fitting, they used an assumption that the redox potential of the $\mathrm{Ni}-\mathrm{R} / \mathrm{Ni}-\mathrm{C}$ couple is far more negative than the potentials range investigated. More sophisticated analysis has also been reported by Léger's group [38] based on the same dispersion model. Although it may be considered that the residual slope is ascribed to the interfacial electron transfer kinetic-controlled catalytic reaction due to unfavorably oriented hydrogenases on the electrode, the sigmoidal part of the catalytic wave may be ascribed predominantly to favorably oriented enzymes and can be explained on a thermodynamic model. 
On the other hand, the Ni-B state (the inactive state with low kinetic barrier for reactivation) is produced, when [NiFe]-hydrogenases are suffered from the highly oxidative stress at electrodes and by oxidized dyes and $\mathrm{O}_{2}[1,37,39]$. This reaction is called as the oxidative inactivation and is an obstacle for constructing an aforementioned bioelectrochemical device for $\mathrm{H}_{2}$ energy conversion. Several kinetic studies have been reported [40-42]. In addition, there are two reports to overcome this reaction $[43,44]$. Schuhmann's and Lubitz's groups have proposed that a new concept to protect hydrogenases against the oxidative inactivation by exploiting a specifically designed viologen-based redox hydrogel [43]. The electron transfer between the polymer-bound viologen moieties controls the potential near the active site of the hydrogenase and thus insulates the enzyme from excessive oxidative stress [43]. On the other hand, we have focused on the reaction mechanism and considered the oxidative inactivation as a competitive inhibition-like reaction against the $\mathrm{H}_{2}$ binding to the Ni-SI state [44]. As far as we know, this is the first report on a description of the pseudo-steady-state current of the oxidative inhibition as a function of the electrode potential and the Michaelis constant. In the dissolved system, the saturated $\mathrm{H}_{2}$ concentration is $740 \mu \mathrm{M}$ at $40^{\circ} \mathrm{C}$ [45], which is only slightly larger than the Michaelis constant $\left(K_{\mathrm{M}}\right.$ $=570 \mu \mathrm{M}$ ) evaluated in DET-type bioelectrocatalysis [41]. To achieve the high $\mathrm{H}_{2}$ concentration, we have constructed a gas-diffusion-type electrode, which can directly supply $\mathrm{H}_{2}$ gas to the enzyme layer on the solution-side of the anode. As a result, the high-speed (non-equilibrated but a steady-state)- $\mathrm{H}_{2}$-supply enhances the $\mathrm{H}_{2}$ concentration around the hydrogenase and thus makes it possible to overcome the oxidative inactivation $[41,44]$.

The inactivation was sometimes analyzed from the thermodynamic point of view, and $E_{\text {switch }}$ is often used as a practical parameter, which is defined as a potential to produce bioelectrocatalytic voltammogram with the maximum slope on the in the reductive activation process (that is, the half-wave potential of bioelectrocatalytic voltammogram in the reductive activation process) [46]. Although the parameter $E_{\text {switch }}$ includes kinetic characteristics as well as thermodynamic ones [40], it was used as a physical index of the oxidative inactivation potential [46]. Therefore, it seems to be important to understand the characteristics of $E_{\text {switch }}$ from the kinetic viewpoints.

In this study, we use an $\mathrm{O}_{2}$-tolerant and membrane-bound [NiFe]-hydrogenase from 
Hydrogenovibrio marinus (HmMBH) [11,12] for thermodynamic and kinetic analysis. First, we have considered the $\mathrm{H}_{2}$-binding to the [NiFe]-active site and the two-step one-electron transfer mechanism in the catalytic cycle for analysis of Nernstian response of DET-type catalytic voltammograms of the $\mathrm{H}_{2}$ oxidation. Second, we have kinetically examined the oxidative inactivation by focusing the time dependence of the steady-state catalytic current in potential-step measurements. Here we use a new model based on the competitive inhibition. Similar to the conclusion on the other reports, the inactivation rate constant does not depend on the electrode potential, and the reactivation rate constant depends on the electrode potential. In other words, the rate-determining steps (r.d.s.) of the inactivation and the reactivation are a chemical process and an electron transfer process, respectively. Here, we also show that the rate constant decreases by immobilizing the enzyme. Based on the kinetics, we will discuss the redox potential concerning the oxidative inactivation. Finally, we have simulated the bioelectrocatalytic cyclic voltammograms of $\mathrm{HmMBH}$ with thermodynamic and kinetic parameters evaluated here. The simulation has well reproduced the fundamental feature of the oxidative inactivation, especially the dependence of the catalytic waves on the scan rate and the hydrogen concentration.

\section{Experimental}

\subsection{Materials}

N-Hydroxy-succinimide (98\%, NHS) was purchased from Sigma-Aldrich Co. (USA). 1-Ethyl-3-(3-dimethylaminopropyl)-carbodiimide hydrochloride (EDC) was purchased from Dojindo Laboratory (Japan). HmMBH was purified according to the literature [12]. All other chemicals used in this study were of analytical grade and all solutions were prepared with distilled water.

\subsection{Preparation of HmMBH-adsorbed electrode}

Gold (Au) electrodes (3 mm in diameter, BAS) were polished with alumina slurry (Buehler, 
$1 \mu \mathrm{m})$, sonicated, and washed with distilled water. A fifteen- $\mu \mathrm{L}$ aliquot of an $\mathrm{HmMBH}$ solution (7 $\mu \mathrm{M}$ dissolved in $10 \mathrm{mM}$ phosphate buffer of $\mathrm{pH}$ 6) was applied on the Au electrodes, and the electrodes were kept in water-saturated atmosphere for $2 \mathrm{~h}$ at room temperature to slowly dry the solvent $\left(1 \mathrm{~L}=1 \mathrm{dm}^{-3}, 1 \mathrm{M}=1 \mathrm{~mol} \mathrm{dm}^{-3}\right)$.

\subsection{Immobilization of HmMBH on Au electrode}

HmMBH adsorbed on Au electrode was chemically immobilized via amide-linkage [47]. After preparing the Au electrode described as in section 2.2, 15- $\mu \mathrm{L}$ of an $H m \mathrm{MBH} /$ reagent solution (7 $\mu \mathrm{M}$ HmMBH, $12 \mathrm{mM}$ EDC, and $6 \mathrm{mM}$ NHS dissolved in $10 \mathrm{mM}$ phosphate buffer of $\mathrm{pH}$ 6) was applied on the Au electrode. The electrodes were kept in water-saturated atmosphere for $2 \mathrm{~h}$ at room temperature to slowly dry the solvent.

\subsection{Electrochemical measurements}

Cyclic voltammetry and chronoamperometry were performed on electrochemical analyzers BAS CV-50W and ALS 714C. An Ag|AgCl|sat. KCl electrode and a Pt wire were used as a reference electrode and a counter electrode, respectively. Measurements described in sections 3.1, 3.2 and 3.3 were carried out in McIlvaine buffer (pH 5-7) at $25 \pm 2{ }^{\circ} \mathrm{C}$, while measurements described in section 3.4 were carried out in $100 \mathrm{mM}$ phosphate buffer (pH 6) at $40 \pm 2{ }^{\circ} \mathrm{C}$.

\subsection{Digital simulation}

Digital simulation of the DET-type bioelectrocatalysis on $\mathrm{HmMBH}$-adsorbed electrode were carried out using a commercial FEM package called COMSOL ${ }^{\circledR}$ Multiphysics 5.0 on a workstation equipped with two Intel Xeon processors and 64 GB RAM.

\section{Results and discussion}


Fig. 1 (solid line) shows cyclic voltammograms (CVs) of dissolved $\mathrm{H}_{2}$ at an $\mathrm{HmMBH}$-adsorbed Au electrode at several scan rates (v). Judging from the comparison with a wave under Ar-atmospheric conditions (broken line), the Faradaic wave is ascribed to the $\mathrm{HmMBH}$-catalyzed $\mathrm{H}_{2}$ oxidation. The $\mathrm{H}_{2}$ oxidation current began to sigmoidally increase from about $-0.5 \mathrm{~V}$. However, the current decreased in the electrode potential range more positive than about $-0.2 \mathrm{~V}$ and recovered in the reverse scan, most notably at deceased scan rates, for example at $\mathrm{V}=5 \mathrm{mV} \mathrm{s}^{-1}$. The phenomenon is ascribed to the oxidative inactivation to generate the Ni-B state and the reductive reactivation (we will discuss this reaction later).

In order to verify the $\mathrm{O}_{2}$-tolerant characteristics of $\mathrm{HmMBH}$, the effects of the $\mathrm{O}_{2}$ addition on the enzyme activity were monitored with chromoamperometry at $-0.2 \mathrm{~V}$. As shown by the chronoamperogram (CA) in Fig. A1, the steady-state current of the catalytic $\mathrm{H}_{2}$ oxidation decreases immediately after the addition of $\mathrm{O}_{2}$ due to the oxidative inactivation. The decreased current gradually recovers to the original level by the $\mathrm{H}_{2}$-flushing. The characteristics are coincident with those of the typical $\mathrm{O}_{2}$-tolerant hydrogenases [1].

Here, let us consider the r.d.s. of the DET-type bioelectrocatalysis with HmMBH. The bioelectrocatalysis is composed of three steps in series: the substrate diffusion, the enzyme reaction, and the electrode reaction. Concerning the substrate diffusion, we examined the effects of the electrode-rotating rate $(\omega)$ on the catalytic $\mathrm{H}_{2}$ oxidation current. Fig. A2 (A) shows $\mathrm{CV}$ where the $\mathrm{HmMBH}$-adsorbed Au electrode starts to rotate at $\omega=1000 \mathrm{rpm}$ at $-0.2 \mathrm{~V}$ in the forward scan. The electrode rotation causes no effects on the CV shape. Fig. A2 (B) shows the CA at $-0.2 \mathrm{~V}$ where the $\omega$ values of $\mathrm{HmMBH}$-adsorbed Au electrode were changed from 0 to 1000, 2000, and 3000 rpm, respectively. The steady-state current is independent of $\omega$. These facts show that the mass transfer is much faster than other processes.

Concerning the enzyme reaction and the electrode reaction, it is difficult to simply separate the contributions of these reactions on the current. The gradual increase (called the residual slope) in the catalytic current (at potentials more positive than $-0.3 \mathrm{~V}$ in Fig. 1) is ascribed to $\mathrm{HmMBH}$ unfavorably oriented for DET [35,37,38]. Léger's group has considered the effect of a dispersion of 
the interfacial electron transfer rates on the voltammograms by assuming the uniform disorder of the distance between the electrode and the active site of the enzyme $[35,37,38]$. Based on this model, they have analyzed the voltammograms with residual slopes and have succeeded in evaluation of enzyme characteristics.

The sigmoidal part in the catalytic steady-state $\mathrm{CV}(-0.5$ to $-0.3 \mathrm{~V}$ in Fig. 1) is predominantly ascribed to the favorably oriented $\mathrm{HmMBH}$ and that the part may be simply analyzed from the thermodynamic viewpoint $[18,35]$. Here, we consider a model similar to that of Léger's group [18]. In the model, it is assumed that spherical enzymes are "randomly" adsorbed on an electrode (Fig. A3) with one-step electron transfer site. Appendix A summarizes the derivation of Eq. (A.8) which can describe the shapes of the steady-state catalytic wave. As shown in Fig. A4, the sigmoidal part becomes quite clear as an increase in $k_{\text {max }}^{\circ} / k_{\mathrm{c}}$, where $k_{\text {max }}^{\circ}$ and $k_{\mathrm{c}}$ are the standard rate constant for the electrode reaction at a distance of the closest approach and the catalytic constant of the enzyme, respectively. Here, let us consider the contributions of the catalytic reaction by the favorably oriented enzymes on the sigmoidal part at a large $k_{\max }^{\circ} / k_{\mathrm{c}}$. We tentatively selected the enzymes with $\theta^{\prime}$ in a range of $0 \leq \theta^{\prime} \leq \pi / 4$ as the favorably oriented ones, where $\theta^{\prime}$ is the angle between the vertical axis and the line from the center of the enzyme to the redox center (Fig. A3). The other part of the randomly oriented enzymes with $\pi / 4 \leq \theta^{\prime} \leq \pi$ were considered as the unfavorably oriented enzymes. The total value of the steady-state catalytic current was divided into two contributions from the favorably oriented enzymes and the unfavorably oriented enzymes. As shown in Fig. A5, the sigmoidal part of the voltammogram is predominantly contributed from the favorably oriented enzymes with a very large $k^{\circ}{ }_{\max } / k_{\mathrm{c}}$. Therefore, as the first approximation, we can assume that the sigmoidal part of the steady-state catalytic CV (in the potential range from -0.5 to $-0.3 \mathrm{~V}$ in $\mathrm{CV}$ in Fig. 1 ) is predominantly produced by the catalytic reaction of the favorably oriented enzymes which can reversibly communicate with the electrode. This consideration means that the redox states of the favorably oriented $\mathrm{HmMBH}$ is completely governed by the electrode potential, and that the catalytic current is proportional to the Michaelis complex formed from the Ni-SI state and $\mathrm{H}_{2}$ on the electrode surface. 
We perform the Nernst analysis for the voltammograms of the $\mathrm{HmMBH}$-catalyzed $\mathrm{H}_{2}$ oxidation in the potential range from -0.5 to $-0.3 \mathrm{~V}$, where the oxidative inactivation does not occur (or the inactivation may be ignored, if any). For the $\mathrm{H}_{2}$ oxidation, the catalytic cycle can be written, as shown in Scheme 2. Since the binding positions between Ni and Fe atoms of the Ni-R and Ni-C states are occupied, $\mathrm{H}_{2}$ seems to bind to the Ni-SI state only [1-3]. The Ni-SI:H $\mathrm{H}_{2}$ complex corresponds the Michaelis complex essentially used in the enzyme kinetics. B. L. Greene et al. have also assumed the presence of $\mathrm{H}_{2}$-complex with Ni-SI state in the enzyme kinetic analysis [48]. Considering the Ni-SI:H $\mathrm{H}_{2}$ complex formation and a steady-state approximation, the steady-state catalytic current of the $\mathrm{HmMBH}$-catalyzed $\mathrm{H}_{2}$ oxidation ( $i_{\text {cat }}$ ) in the presence of excess amounts of $\mathrm{H}_{2}$ can be expressed by Eq. (1)

$$
i_{\text {cat }}=n F A k_{\mathrm{c}} \Gamma_{\mathrm{Ni}-\mathrm{SI}: \mathrm{H}_{2}}
$$

Where $n, F, A$, and $\Gamma_{\text {Ni-SI:H }}$ are, respectively, the number of electrons (2 in this case), the Faraday constant, the projected electrode surface area, and the surface concentration of the active Ni-SI: $\mathrm{H}_{2}$ state. The limiting catalytic current $\left(i_{\text {lim }}\right)$ is given by Eqs. (2) and (3) similar to the Michaelis-Menten equation

$$
i_{\text {lim }}=\frac{n F A k_{\mathrm{c}} \Gamma_{\text {total }}}{1+\frac{K_{\mathrm{M}}}{c_{\mathrm{H}_{2}}}}
$$

while $\Gamma_{\text {total }}$ is the total surface concentration of the effective $H m \mathrm{MBH}$ given by

$$
\Gamma_{\text {total }}=\Gamma_{\mathrm{Ni}-\mathrm{SI}: \mathrm{H}_{2}}+\Gamma_{\mathrm{Ni}-\mathrm{SI}}+\Gamma_{\mathrm{Ni}-\mathrm{C}}+\Gamma_{\mathrm{Ni}-\mathrm{R}}
$$

where $K_{\mathrm{M}}, c_{\mathrm{H}_{2}}, \Gamma_{\mathrm{Ni}-\mathrm{SI}}, \Gamma_{\mathrm{Ni}-\mathrm{C}}$, and $\Gamma_{\mathrm{Ni}-\mathrm{R}}$ are, respectively, the Michaelis constant, the concentration of dissolved $\mathrm{H}_{2}$, and the surface concentrations of the Ni-SI, Ni-C and Ni-R states. The Nernstian distribution of the Ni-SI, Ni-C, and Ni-R states (Eqs. (4) and (5)) and the distribution ratio of Ni-SI and Ni-SI:H $\mathrm{H}_{2}$ complex (Eq. (6)) are given as follows:

$$
\begin{aligned}
& \frac{\Gamma_{\mathrm{Ni}-\mathrm{SI}}}{\Gamma_{\mathrm{Ni}-\mathrm{C}}}=\exp \left\{\frac{F}{R T}\left(E-E^{\mathrm{O}}{ }_{\mathrm{Ni}-\mathrm{C} / \mathrm{Ni}-\mathrm{SI}}\right)\right\} \equiv e_{\mathrm{Ni}-\mathrm{C} / \mathrm{Ni}-\mathrm{SI}} \\
& \frac{\Gamma_{\mathrm{Ni}-\mathrm{C}}}{\Gamma_{\mathrm{Ni}-\mathrm{R}}}=\exp \left\{\frac{F}{R T}\left(E-E^{\mathrm{O}}{ }_{\mathrm{Ni}-\mathrm{R} / \mathrm{Ni}-\mathrm{C}}\right)\right\} \equiv e_{\mathrm{Ni}-\mathrm{R} / \mathrm{Ni}-\mathrm{C}}
\end{aligned}
$$




$$
\frac{\Gamma_{\mathrm{Ni}-\mathrm{SI}}}{\Gamma_{\mathrm{Ni}-\mathrm{SI}: \mathrm{H}_{2}}}=\frac{K_{\mathrm{M}}}{C_{\mathrm{H}_{2}}}
$$

where $R, T, E, E^{\circ 1}{ }_{\mathrm{Ni}-\mathrm{C} / \mathrm{Ni}-\mathrm{SI}}$, and $E^{\mathrm{O}_{\mathrm{Ni}-\mathrm{R} / \mathrm{Ni}-\mathrm{C}}}$ are, respectively, the gas constant, the absolute temperature, the electrode potential, and the formal redox potentials of the $\mathrm{Ni}-\mathrm{C} / \mathrm{Ni}-\mathrm{SI}$ and Ni-R/Ni-C redox couples. Therefore, the normalized steady-state catalytic current $\left(i_{\text {cat }} / i_{\text {lim }}\right)$ can be expressed by:

$$
\begin{aligned}
\frac{i_{\mathrm{cat}}}{i_{\mathrm{lim}}}= & \frac{\Gamma_{\mathrm{Ni}-\mathrm{SI}: \mathrm{H}_{2}}\left(1+\frac{K_{\mathrm{M}}}{C_{\mathrm{H}_{2}}}\right)}{\Gamma_{\text {total }}} \\
= & \frac{\Gamma_{\mathrm{Ni}-\mathrm{SI}: \mathrm{H}_{2}}\left(1+\frac{K_{\mathrm{M}}}{C_{\mathrm{H}_{2}}}\right)}{\Gamma_{\mathrm{Ni}-\mathrm{SI}: \mathrm{H}_{2}}+\Gamma_{\mathrm{Ni}-\mathrm{SI}}+\Gamma_{\mathrm{Ni}-\mathrm{C}}+\Gamma_{\mathrm{Ni}-\mathrm{R}}} \\
= & \frac{1+\frac{K_{\mathrm{M}}}{C_{\mathrm{H}_{2}}}}{1+\frac{K_{\mathrm{M}}}{C_{\mathrm{H}_{2}}}\left(1+\frac{1}{e_{\mathrm{Ni}-\mathrm{R} / \mathrm{Ni}-\mathrm{C}}}+\frac{1}{e_{\mathrm{Ni}-\mathrm{R} / \mathrm{Ni}-\mathrm{C}} e_{\mathrm{Ni}-\mathrm{C} / \mathrm{Ni}-\mathrm{SI}}}\right)}
\end{aligned}
$$

A normalized Faradaic voltammogram is given in Fig. 2 as open circles by pre-subtracting the charging current from the voltammogram (Fig. 1, forward scan, $\mathrm{v}=5 \mathrm{mV} \mathrm{s}^{-1}$ ) and normalizing the current with $i_{\text {lim. }}$ Eq. (7) was fitted to the data with $E^{01}{ }_{\text {Ni-C/Ni-SI }}$ and $E^{{ }^{\circ}}{ }_{\text {Ni-R/Ni-C }}$ as the adjustable parameters by using a non-linear regression program Gnuplot ${ }^{\circledR}$. The regression yielded the result that $E^{\circ}{ }_{\mathrm{Ni}-\mathrm{C} / \mathrm{Ni}-\mathrm{SI}}=-364 \pm 1 \mathrm{mV}$ and that $E^{\circ{ }_{\mathrm{Ni}-\mathrm{R} / \mathrm{Ni}-\mathrm{C}}}=-466 \pm 9 \mathrm{mV}$, and the regression curve is given in Fig. 2 as a solid line. The similar analysis was performed for the other voltammograms measured at various pHs (5-7), and the results are collected in Fig. 3. This is the first report on the Nernst analysis of the sigmoidal part in the catalytic wave of hydrogenases.

The redox potentials of $\mathrm{O}_{2}$-tolerant [NiFe]-hydrogenase from A. aeolicus were reported in the literature [42]. At $\mathrm{pH} \mathrm{6,}{E^{\circ}}^{\mathrm{\prime}}{ }_{\mathrm{Ni}-\mathrm{R} / \mathrm{Ni}-\mathrm{C}}$ of $\mathrm{HmMBH}(=-510 \pm 20 \mathrm{mV}$ vs. Ag|AgCl|sat. $\mathrm{KCl})$ is similar to that of [NiFe]-hydrogenase from A. aeolicus $(=-489 \mathrm{mV})$. On the other hand, $E^{\circ{ }^{\prime}{ }_{\mathrm{Ni}-\mathrm{C} / \mathrm{Ni}-\mathrm{SI}}}$ of $\mathrm{HmMBH}(=-381 \pm 1 \mathrm{mV})$ is different from that of [NiFe]-hydrogenase from A. aeolicus ( -421 $\mathrm{mV}$ ). The discrepancy is due to the difference in the models used for the analysis. Note that we have simply analyzed the voltammograms with Nernst equation on a new model of two-step electron transfer without interfacial electron transfer kinetic contribution, but by considering the 
$\mathrm{H}_{2}$-binding.

\subsection{Pourbaix diagram of the Ni-SI, Ni-C, and Ni-R}

The closed triangles in Fig. 3 indicate the half-wave potential in the sigmoidal response (Fig. 2). The $\mathrm{pH}$ dependence seems to be about $-30 \mathrm{mV} / \mathrm{pH}$ as a whole. This suggests that number of the proton $(\mathrm{m})$ in the overall $2 \mathrm{e}^{-}$transfer is one as judged from the theoretical value 2.303 $(R T / F)(m / n)$ ( $n$ being the number of electron of the total process, $n=2$ in this case). However, as shown in Fig. 3, both of $E^{01}{ }_{\mathrm{Ni}-\mathrm{C} / \mathrm{Ni}-\mathrm{SI}}$ and $E^{\mathrm{O}}{ }_{\mathrm{Ni}-\mathrm{R} / \mathrm{Ni}-\mathrm{C}}$ depend on $\mathrm{pH}$. Therefore, we have to consider the $\mathrm{pH}$ dependence of $E^{01}{ }_{\mathrm{Ni}-\mathrm{C} / \mathrm{Ni}-\mathrm{SI}}$ and ${E^{\circ}}_{\mathrm{Ni}-\mathrm{R} / \mathrm{Ni}-\mathrm{C}}$ as a combination of lines with slopes of -60 $\mathrm{mV} / \mathrm{pH}$ and $0 \mathrm{mV} / \mathrm{pH}$

( $m=1$ or $0, n=1$ ). This means that the two one-electron transfer processes are coupled with the acid dissociation of the Ni-SI, Ni-C and Ni-R states. Since the Ni-C state is involved in both of the redox couples, the acid dissociation constant of the $\mathrm{Ni}-\mathrm{C}$ state affects both of the formal redox potential of the Ni-C/Ni-SI and Ni-R/Ni-C redox couples. For this reason, we first analyzed the Ni-C/Ni-SI redox couple. As judged from Fig. 3 (open circle), it is reasonable to assume that at least two acid dissociations for the Ni-SI state and one acid dissociation for the $\mathrm{Ni}-\mathrm{C}$ state are involved in the electron transfer. Under the assumption, the $\mathrm{pH}$ dependence of the formal redox potential of the $\mathrm{Ni}-\mathrm{C} / \mathrm{Ni}-\mathrm{SI}$ redox couple ( $\left.E^{\mathrm{O}}{ }_{\mathrm{Ni}-\mathrm{C} / \mathrm{Ni}-\mathrm{SI}, \text { app }}\right)$ is expressed by

$$
E_{\text {Ni-C/Ni-SI, app }}^{\circ}=\frac{2.303 R T}{F}\left\{\begin{array}{l}
\log \left(1+10^{\mathrm{pH}-\mathrm{p} K_{\mathrm{a}, \mathrm{Ni}-\mathrm{C}_{1}}}\right) \\
-\log \left(1+10^{\mathrm{pH}-\mathrm{p} K_{\mathrm{a}, \mathrm{N}-\mathrm{SI}}}+10^{2 \mathrm{pH}-\mathrm{p} K_{\mathrm{a}, \mathrm{Ni}-\mathrm{SI}_{1}-\mathrm{p} K_{\mathrm{a}, \mathrm{N}-\mathrm{SI}}}}\right)
\end{array}\right\}+C_{1}
$$

where $\mathrm{p} K_{\mathrm{a}, \mathrm{Si}}$ is the ith dissociation constant for the state $\mathrm{S}(\mathrm{S}=\mathrm{Ni}-\mathrm{SI}, \mathrm{Ni}-\mathrm{C}$, or Ni-R). Eq. (8) was fitted to the $E^{\circ{ }^{\circ}{ }_{\mathrm{N}-\mathrm{C} / \mathrm{Ni} \text {-SI, app }}}$ Vs. $\mathrm{pH}$ profile evaluated by the non-linear regression analysis of the steady-state catalytic voltammograms with three dissociation constants $\left(\mathrm{p} K_{\mathrm{a}, \mathrm{Ni}_{-} \mathrm{C}_{1}}, \mathrm{p} K_{\mathrm{a}, \mathrm{Ni}-\mathrm{SI}_{1}}\right.$ and $\left.\mathrm{pK}_{\mathrm{a}, \mathrm{Ni}-\mathrm{SI}_{2}}\right)$ and $C_{1}$ as the adjustable parameters. The data are well reproduced by Eq. (8), as shown in Fig. 3. The refined parameters are: $\mathrm{p} K_{\mathrm{a}, \mathrm{Ni}-\mathrm{C}_{1}}=6.0 \pm 0.1, \mathrm{p} K_{\mathrm{a}, \mathrm{Ni}-\mathrm{SI}_{1}}=5.1 \pm 0.1$ and $\mathrm{p} K_{\mathrm{a}, \mathrm{Ni}-\mathrm{SI}_{2}}=6.9 \pm 0.1$.

Similar analysis was performed to the formal potential of the $\mathrm{Ni}-\mathrm{R} / \mathrm{Ni}-\mathrm{C}$ redox couple ( $E_{\mathrm{Ni}-\mathrm{R} / \mathrm{Ni}-\mathrm{C}, \mathrm{app}}^{\mathrm{o}}$ ). As judged from Fig. 3 (open triangle), we may assume that at least one acid dissociation for the Ni-C state and two acid dissociations for the Ni-R state are involved in the 
electron transfer. The corresponding equation of the $\mathrm{pH}$ dependence of $E^{\mathrm{or}}{ }_{\mathrm{Ni}-\mathrm{R} / \mathrm{Ni}-\mathrm{C} \text {, app }}$ is given by:

$$
E_{\text {Ni-R/Ni-C, app }}^{\circ}=\frac{2.303 R T}{F}\left\{\begin{array}{l}
\log \left(1+10^{\mathrm{pH}-\mathrm{p} K_{\mathrm{a}, \mathrm{N}-\mathrm{R}_{1}}}+10^{2 \mathrm{pH}-\mathrm{p} K_{\mathrm{a}, \mathrm{N}-\mathrm{R}_{1}}-\mathrm{p} K_{\mathrm{a}, \mathrm{Ni}-\mathrm{R}_{2}}}\right) \\
-\log \left(1+10^{\mathrm{pH}-\mathrm{p} K_{\mathrm{a}, \mathrm{Ni}-\mathrm{C}_{1}}}\right)-\mathrm{pH}
\end{array}\right\}+C_{2}
$$

Since $\mathrm{p} K_{\mathrm{a}, \mathrm{Ni}-\mathrm{C}_{1}}$ can be set as 6.0 as evaluated in the analysis of $E^{\mathrm{or}}{ }_{\mathrm{Ni}-\mathrm{C} / \mathrm{Ni}-\mathrm{SI}, \text { app }}, \mathrm{p} K_{\mathrm{a}, \mathrm{Ni}-\mathrm{R}_{1}}$, and $\mathrm{p} K_{\mathrm{a}, \mathrm{Ni}-\mathrm{R}_{2}}$ values were evaluated by non-linear regression analysis to get about 5.6 and 6.5, respectively.

Since the electron density of the amino acid residues around the [NiFe]-active site will increase with the reduction proceeds, the $\mathrm{pK}_{\mathrm{a}}$ of the given site should increase on the reduction. Therefore, we may assign $\mathrm{p}_{\mathrm{a}, \mathrm{Ni}-\mathrm{SI}_{1}}, \mathrm{p} K_{\mathrm{a}, \mathrm{Ni}-\mathrm{C}_{1}}$, and $\mathrm{p} K_{\mathrm{a}, \mathrm{Ni}-\mathrm{R}_{2}}$ to one identical amino acid residue. In contrast, $\mathrm{p} K_{\mathrm{a}, \mathrm{Ni}-\mathrm{SI}_{2}}$ and $\mathrm{p} K_{\mathrm{a}, \mathrm{Ni}-\mathrm{R}_{1}}$ seem to be assigned to different amino acid residues, respectively. Although it is difficult to clearly distinguish and assign them at this stage, one of possible candidates of the amino acid residue around the [NiFe]-active site is the Cys residues coordinating to the Ni or Fe atoms [49]. This is the first report on the Pourbaix diagram of the Ni-SI, $\mathrm{Ni}-\mathrm{C}$, and Ni-R states based on the thermodynamic theory.

\subsection{Kinetic analysis on the oxidative inactivation}

As described in Introduction, we have performed kinetic analysis on the oxidative inactivation of $\mathrm{HmMBH}$ adsorbed on Au electrode and meso-porous carbon electrode (Ketjen Black is used as an electrode material) [41]. In this study, we performed the same analysis on $\mathrm{HmMBH}$ chemically immobilized on Au electrode. $\mathrm{HmMBHs}$ on the Au electrode were bound with each other through amide-linkage. According to a previous study [41], we assumed a reversible (two-way) first-order reaction between the active (Ni-SI) and inactive (Ni-B) states of the enzyme with two rate constants $\left(k_{\mathrm{I}}\right.$ and $k_{\mathrm{A}}$ ), as shown in Scheme $1, k_{\mathrm{I}}$ and $k_{\mathrm{A}}$ being the apparent rate constants of inactivation and reactivation, respectively. The initial potential $\left(E_{1}\right)$ was set at $-0.2 \mathrm{~V}$, where the oxidative inactivation does not occur (or can be ignored) at $\mathrm{pH} 6$ and the maximum catalytic current $\left(i_{0}\right)$ was defined. After the potential was stepped at $t=0$ to a given potential $\left(E_{2}\right)$, at which the oxidative inactivation proceeds. The open circles in Fig. 4 indicate a CA of the $\mathrm{H}_{2}$ oxidation current at the chemically immobilized $\mathrm{HmMBH}$-modified Au electrode at $E_{2}=-0.02 \mathrm{~V}$. 
The data just after the potential step involve the charging current and then were eliminated from the present analysis. As shown in previous studies [40-42], the decay of the catalytic current is given by

$$
i_{\text {cat }}(t)=i_{0}\left\{\frac{k_{\mathrm{I}}}{k_{\mathrm{I}}+k_{\mathrm{A}}} \exp \left[-\left(k_{\mathrm{I}}+k_{\mathrm{A}}\right) t\right]+\frac{k_{\mathrm{A}}}{k_{\mathrm{I}}+k_{\mathrm{A}}}\right\}
$$

Eq. (10) was fitted to the data in Fig. 4 with $i_{0}, k_{\mathrm{I}}$, and $k_{\mathrm{A}}$ as the adjustable parameters by using Gnuplot $^{\circledR}$. The regression curve is shown in Fig. 4 as a solid curve. The similar analysis was conducted at several $E_{2}$ values, and the potential dependence of $k_{\mathrm{I}}$ and $k_{\mathrm{A}}$ is given in Fig. 5 as triangles. The open circles correspond to the results obtained at $\mathrm{HmMBH}$-adsorbed Au electrode.

Comparing the results of two $\mathrm{HmMBH}$-modified Au electrodes, the evaluated values of $k_{\mathrm{I}}$ are independent of the electrode potential $(E)$. The fact indicates that the r.d.s. of the inactivation is non-electron transfer chemical process. In addition, the chemical immobilization decreases the rate constant of the chemical process. Similar decrease in $k_{\mathrm{I}}$ was observed by adsorption of $\mathrm{HmMBH}$ on meso-porous material [41]. The chemical immobilization as well as adsorption on meso-porous material seems to cause the deceleration of the hydroxide ligand coordination to the [NiFe]-active site (the coordination of water on it and the succeeding deprotonation). The incorporation of water or the some kind of conformational changes seems to be the r.d.s. in the hydroxide ligand coordination. As to the latter reaction, the possible rate-determining chemical reaction seems to be the conformational change around the [NiFe]-active site. On the other hand, it is known that the unique proximal [FeS]-cluster of the $\mathrm{O}_{2}$-tolerant hydrogenase changes to the superoxidation state on the attack of $\mathrm{O}_{2}$ to overcome the irreversible inactivation (formation of the Ni-A state) and to form the Ni-B state [11]. Therefore, the rate-determining chemical process may be also related to the conformational change around the [FeS]-clusters.

In contrast, the logarithmic values of $k_{\mathrm{A}}$ decrease linearly with an increase in $E$ and reach a corresponding limiting value at high potentials $(E>0.05 \mathrm{~V})$. The $k_{\mathrm{A}}$ values in the exponential dependence against $E(-0.12 \mathrm{~V}<E<-0.05 \mathrm{~V})$ are not affected by the chemical immobilization. We can say that the r.d.s. of the reactivation is one-electron reduction of the Ni(III) atom in the Ni-B state.

Concerning the dependence of $k_{\mathrm{I}}$ and $k_{\mathrm{A}}$ on the electrode potential, similar discussion has been demonstrated for $\mathrm{O}_{2}$-tolerant [NiFe]-hydrogenase from A. aeolicus [42]. For instance, $k_{\mathrm{I}}$ and $k_{\mathrm{A}}$ of the [NiFe]-hydrogenase are, respectively, around $0.002 \mathrm{~s}^{-1}$ and $0.02 \mathrm{~s}^{-1}$ at $E=0.1 \mathrm{~V}$ vs. SHE (- 
$0.1 \mathrm{~V}$ vs. $\mathrm{Ag}|\mathrm{AgCl}|$ sat. $\mathrm{KCl}$ ) (note that the experience was carried out at $\mathrm{pH} 6,1 \mathrm{~atm} \mathrm{H}_{2}$, and $40{ }^{\circ} \mathrm{C}$ ). Consequently, we can say that $k_{\mathrm{I}}\left(=0.14 \mathrm{~s}^{-1}\right)$ and $k_{\mathrm{A}}\left(=0.16 \mathrm{~s}^{-1}\right)$ of $\mathrm{HmMBH}$ at $E=-0.1 \mathrm{~V}$ (vs. $\mathrm{Ag}|\mathrm{AgCl}|$ sat. $\mathrm{KCl}$ ) shown in Fig. 5 are much larger than those of [NiFe]-hydrogenase from $A$. aeolicus. However, we cannot elucidate the differences at this stage.

As discussed in the above paragraphs, the oxidative inactivation is composed of two processes: the electron transfer process (one-electron oxidation of the $\mathrm{Ni}$ atom) and non-electron transfer chemical process (coordination of hydroxide ligand on the [NiFe]-active site). Consequently, $k_{\mathrm{I}}$ and $k_{\mathrm{A}}$ can be expressed by Eqs. (11) to (14)

$$
\begin{aligned}
& \frac{1}{k_{\mathrm{I}}}=\frac{1}{k_{\mathrm{I}, \text { elec }}(E)}+\frac{1}{k_{\mathrm{I}, \text { chem }}} \\
& k_{\mathrm{I}} \approx k_{\mathrm{I}, \text { chem }}(E>-0.2 \mathrm{~V}) \\
& \frac{1}{k_{\mathrm{A}}}=\frac{1}{k_{\mathrm{A}, \text { elec }}(E)}+\frac{1}{k_{\mathrm{A}, \text { chem }}} \\
& k_{\mathrm{A}} \approx k_{\mathrm{A}, \text { elec }}(E)(-0.02 \mathrm{~V}>E>-0.2 \mathrm{~V})
\end{aligned}
$$

where $k_{\mathrm{I} \text {,elec }}(E), k_{\mathrm{I}, \text { chem }}, k_{\mathrm{A} \text {, elec }}(E)$, and $k_{\mathrm{A} \text {, chem }}$ are the rate constants of the electron transfer reaction and the chemical (non-electron transfer) reaction of the inactivation or reactivation, respectively.

Here, we assume a model reaction, as shown in Scheme 3. The parameters $k_{1}$ and $k_{-1}$ are, respectively, the forward and backward rate constants of the $\mathrm{H}_{2}$-binding, and are defined as

$$
K_{\mathrm{M}}=\frac{k_{-1}}{k_{1}}
$$

According to our competitive inhibition-like model (Scheme 3), the parameters $k_{2}$ and $k_{-2}$ are, respectively, the true rate constants of the inactivation and reactivation, and are defined as [41]

$$
\begin{aligned}
& k_{2}=k_{\mathrm{I}} \\
& \mathrm{k}_{-2}=\frac{\mathrm{k}_{\mathrm{A}}}{1+\frac{\mathrm{C}_{\mathrm{H}_{2}}}{\mathrm{~K}_{\mathrm{M}}}}
\end{aligned}
$$

Here, we can reasonably assume that the true rate constant of the electrochemical oxidation of Ni-SI 
$\left(k_{2, \text { elec }}\right)$ is equal to that of the reduction of $\mathrm{Ni}-\mathrm{B}\left(k_{-2, \text { elec }}\right)$ at the formal potential of the oxidative inactivation ( $\left.E^{\mathrm{O}}{ }_{\mathrm{Ni}-\mathrm{SI} / \mathrm{Ni}-\mathrm{B}}\right)$ Therefore,

$$
\frac{k_{2, \text { elec }}}{k_{-2, \text { elec }}} \equiv \frac{k_{\mathrm{I}, \text { elec }}}{k_{\mathrm{A} \text {,elec }}}\left(1+\frac{c_{\mathrm{H}_{2}}}{K_{\mathrm{M}}}\right)=1
$$

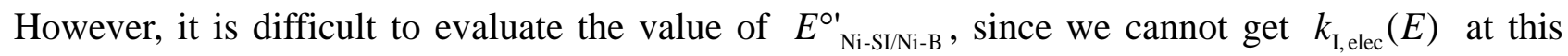
stage. According to the definition of $E_{\text {switch }}$ [46] (see also Introduction), $E_{\text {switch }}$ is evaluated as $0.12 \mathrm{~V}$ in our case, as judged from the $\mathrm{CV}$ at $\mathrm{v}=5 \mathrm{mV} \mathrm{s}^{-1}$ in Fig. 1 . The value of $\log k_{\mathrm{A}}$ in Fig. 5 (B) is extrapolated to about -0.7 at $-0.12 \mathrm{~V}$. When we use $0.57 \mathrm{mM}$ for $K_{\mathrm{M}}$ in the case of $H m \mathrm{MBH}$ and $0.74 \mathrm{mM}$ for the saturated $\mathrm{C}_{\mathrm{H}_{2}}$ at $40{ }^{\circ} \mathrm{C}$ [45], $\log k_{\mathrm{I}, \text { elec }}$ can be estimated to be about -1.0 at $0.12 \mathrm{~V}$ by using Eqs. (14) and (18). This value is much smaller than that of $\log k_{\mathrm{I}}(\approx-0.85)$ at -0.12 V (Fig. 5 (A)). The situation does not satisfy Eq. (12) (note that the r.d.s. of the inactivation is the non-electron transfer chemical process). To satisfy Eq. (12), $\mathrm{k}_{\mathrm{I}, \text { elec }}$ should be much larger than $\mathrm{k}_{\mathrm{I}, \text { chem }}$. Such situation will be realized at more negative potentials than $-0.12 \mathrm{~V}\left(=E_{\text {switch }}\right)$. For example, $\log k_{\mathrm{A}}$ in Fig. 5 (B) is extrapolated to about -0.2 at $-0.2 \mathrm{~V}$, and then $\log k_{\mathrm{I}, \text { elec }}$ should be about -0.5 at $-0.2 \mathrm{~V}$ by using Eq. (18). This situation can satisfy Eq. (12) and $E^{\mathrm{or}}{ }_{\text {Ni-SI/Ni-B }}$ will locate around $-0.2 \mathrm{~V}$. In conclusion, $E^{\mathrm{O}}{ }_{\mathrm{Ni}-\mathrm{SI} / \mathrm{Ni}-\mathrm{B}}$ is more negative than $E_{\text {switch }}$. This conclusion is in consistence with that in the literature [40]

\subsection{Digital simulation of bioelectrocatalytic CVs with $\mathrm{HmMBH}$}

As mentioned in Introduction, it is reasonable to consider the oxidative inactivation as a competitive inhibition-like reaction. $\mathrm{HmMBH}$ adsorbed on the electrode has several states affected by, for instance, the electrode potential and the substrate concentration. Under such conditions, the shape of bioelectrocatalytic CVs with adsorbed $\mathrm{HmMBH}$ results in the complicated one, as shown in Fig. 1 (solid line). On the other hand, Léger's group simulated the CVs of [NiFe]-hydrogenase from A. aeolicus on the dispersion model with apparent rate constants of the inactivation and reactivation [42]. Since we have evaluated the thermodynamic property of the catalytic cycle ( $E_{\mathrm{Ni}-\mathrm{C} / \mathrm{Ni}-\mathrm{SI}, \text { app }}^{\mathrm{o}}$ and $\left.E^{\mathrm{O}}{ }_{\mathrm{Ni}-\mathrm{R} / \mathrm{Ni}-\mathrm{C}, \text { app }}\right)$ and the true kinetic property of the reversible inactivation $\left(k_{2}\right.$ and $k_{-2}$ ) in the above sections, we attempted to simulate the CV based on the above analysis. The parameters $k_{3}, k_{-3}, k_{4}$ and $k_{-4}$ in Scheme 3 are, respectively, the electrode reaction rate 
constants of Ni-C/Ni-SI and Ni-R/Ni-C redox couples, and are expressed by Butler-Volmer equation (by assuming the transfer coefficient as 0.5) as:

$$
\begin{aligned}
& k_{3}=k^{\circ} \exp \left[\frac{F}{2 R T}\left(E-E_{\text {Ni-C/Ni-SI }}^{\circ}\right)\right] \\
& k_{-3}=k^{\circ} \exp \left[\frac{-F}{2 R T}\left(E-E_{\text {Ni-C/Ni-SI }}^{\circ}\right)\right] \\
& k_{4}=k^{\circ} \exp \left[\frac{F}{2 R T}\left(E-E^{\circ}{ }^{\circ}{ }_{\mathrm{Ni}-\mathrm{R} / \mathrm{Ni}-\mathrm{C}}\right)\right] \\
& k_{-4}=k^{\circ} \exp \left[\frac{-F}{2 R T}\left(E-E^{\circ}{ }_{\mathrm{Ni}-\mathrm{R} / \mathrm{Ni}-\mathrm{C}}\right)\right]
\end{aligned}
$$

Since the interfacial electron transfer process of the favorably oriented $\mathrm{HmMBH}$ is reversible (Nernst response) as mentioned in section 3.1, we assumed the very fast electron transfer by tentatively setting the standard rate constant $\left(k^{\circ}\right)$ as $10000 \mathrm{~s}^{-1}$. Furthermore, we also tentatively set $k_{-1}$ as $100 \mathrm{~s}^{-1}$, which is much larger than the value of $k_{\mathrm{c}}$ to achieve the rapid equilibrium in the $\mathrm{H}_{2}$-binding reaction to the Ni-SI state. Note that the value of $k_{\text {cat }}$ is tentatively set to satisfy that $k^{\circ}>>k_{\text {cat }}$, because the current is simply proportional to $k_{\mathrm{cat}} \Gamma$. In other words, here, we only focused on the shape of CVs in this simulation. Concerning the $k_{2}$ and $k_{-2}$, we estimated the values from the analytical results (Fig. 5). $k_{\mathrm{I}}=10^{-0.85} \mathrm{~s}^{-1}$ calculated from Fig. 5 (A), and $k_{\mathrm{A}}=10^{-8 E-1.6} \mathrm{~s}^{-1}$ calculated from the linear range of Fig. 5 (B) $(-0.11$ to $-0.08 \mathrm{~V})$.

Under the aforementioned conditions, we simulated the $\mathrm{H}_{2}$ oxidation of the DET-type bioelectrocatalysis with adsorbed $\mathrm{HmMBH}$ at pH 6. Simulated CVs (from -0.6 to $0 \mathrm{~V}$ ) with several scan rates are shown in Fig. 6. The simulated CVs can well reproduce the experimental CVs. The scan rate-independent sigmoidal increase in the catalytic wave (of which the characteristics show that $k^{\circ}$ is high enough to realize Nernst response) and the hysteresis in the reversible oxidative inactivation are well reproduced, although the "residual slope" after the sigmoidal increase was ignored in the present analysis. In addition, the reductive reactivation is notable at $\mathrm{v}=5 \mathrm{mV} \mathrm{s}^{-1}$. The results support the validity of the present analysis of the thermodynamics of the catalytic cycle and the kinetics of the oxidative inactivation in DET-type bioelectrocatalysis with adsorbed $\mathrm{HmMBH}$. 
We also examined effects of the $\mathrm{H}_{2}$-concentrarion on the shapes of $\mathrm{CVs}$. The simulated CVs with several $\mathrm{H}_{2}$-concentraitons are shown in Fig. 7. We can predict that the increase in the $\mathrm{H}_{2}$-concentration is effective for avoiding the oxidative inactivation. As mentioned in Introduction, we have already shown that the gas-diffusion-type electrode is effective for avoiding the inactivation. The maximum concentration evaluated here is $47.4 \mathrm{mM}$, which is almost as same as that of the $\mathrm{H}_{2}$ gas (by assuming the $\mathrm{H}_{2}$ gas as an ideal gas). Although it is very difficult to define the $\mathrm{H}_{2}$-concentration around the enzyme in the gas-diffusion-type electrode, the simulated CVs (Fig. 7) will be great help for further understanding in the electrochemical phenomena near and on the electrode surface.

\section{Conclusions}

Nernst analysis has been successfully performed for the CVs of $\mathrm{HmMBH}$-catalyzed $\mathrm{H}_{2}$ oxidation by considering the situations that it proceeds in a two-step one-electron transfer mechanism and that the substrate-enzyme complex $\left(\mathrm{Ni}-\mathrm{SI}: \mathrm{H}_{2}\right)$ is assumed as in the steady-state enzyme kinetics. The results have shown that at least three acid dissociation reactions around the [NiFe]-active site are involved in the catalytic cycle. In addition, we have discussed the kinetics of the oxidative inactivation. Based on the kinetic analysis, it can be concluded that the inactivation rate constant is independent of $E$, whereas the reactivation is dependent on $E$. The rate-determining and potential-independent inactivation process seems to be the hydroxide ligand coordination to the [NiFe]-active site. We have shown that the electrode potential (or solution potential) and the $\mathrm{H}_{2}$-concentration near the enzyme strongly affects the inactivation kinetics, and that the inactivation rate constant can be reduced by restricting the enzyme movement by chemical immobilization on planer electrodes as well as physical adsorption on porous electrodes. This means that since the reactivation rate constant is almost independent of the atmosphere around the enzyme, the inhibition constant can be decreased by restricting the enzyme movement, which is very useful in application of this enzyme to bioelectrochemical devices [24-26,41]. We have also give some thermodynamic discussions on the oxidative inactivation at the present stage. Furthermore, by utilizing the resultant thermodynamic and kinetic parameters, we have successfully 
simulated the bioelectrocatalytic CVs at $\mathrm{HmMBH}$-adsorbed electrode. Finally, we have also shown that the increase in the $\mathrm{H}_{2}$-concentration is effective for avoiding the oxidative inactivation.

\section{Appendix A. Theory of steady-state wave catalyzed by randomly oriented sphere enzymes with one-step electron transfer site}

The enzyme adsorbed on the electrode is simplified as a sphere. A polar coordinate system $(r, \theta, \varphi)$ is introduced with the coordinate origin at the center of the enzyme (Fig. A3) in a way similar to that of the literature [18]. The rotation axes of $\theta$ and $\varphi$ are arranged parallel and vertical to the electrode, respectively. Probability distribution with respect to the presence of the active site on the polar coordinate system is defined as the probability density function $f$. When the enzyme is randomly adsorbed in the range of $0 \leq \theta \leq \theta^{\prime}$ and $0 \leq \varphi \leq 2 \pi$, $f$ is written as follows.

$$
f=\frac{\delta\left(r-r_{0}\right) \zeta\left(\theta^{\prime}\right)}{2 \pi r_{0}^{2}\left(1-\cos \theta^{\prime}\right)}
$$

where $r_{0}, \delta\left(r-r_{0}\right)$, and $\zeta\left(\theta^{\prime}\right)$ are, respectively, the distance between the center of the enzyme and the active site, Dirac delta function, and the unstandardized distribution function about $\theta . \zeta\left(\theta^{\prime}\right)$ is equal to 1 in $0 \leq \theta \leq \theta^{\prime}$ and is equal to 0 in $\theta \leq \theta^{\prime}$. The denominator of the right side of Eq. (A.1) is normalization constant derived from the stochastic convergence.

In addition, the catalytic steady-state current $\left(i_{s}\right)$ caused by the DET-type bioelectrocatalysis is written as Eq. (A.2) [50,51].

$$
i_{\mathrm{s}}=\frac{i_{\mathrm{s}}^{\lim }}{1+\frac{k_{\mathrm{c}}}{k_{\mathrm{f}}}+\frac{k_{\mathrm{b}}}{k_{\mathrm{f}}}}
$$

where $i_{\mathrm{s}}^{\lim }, k_{\mathrm{f}}$, and $k_{\mathrm{b}}$ are, respectively, the catalytic current under kinetically-controlled limiting current conditions (without substrate concentration polarization), and forward and backward rate constants for the electrode reaction. $k_{\mathrm{f}}$ and $k_{\mathrm{b}}$ can be expressed with Butler-Volmer equations as follows,

$$
\begin{aligned}
& k_{\mathrm{f}}=k^{\circ} \exp \left\{-\frac{\alpha n_{\mathrm{E}}^{\prime} F}{R T}\left(E-E^{\circ{ }_{\mathrm{E}}}\right)\right\} \\
& k_{\mathrm{b}}=k^{\circ} \exp \left\{-\frac{(1-\alpha) n_{\mathrm{E}}^{\prime} F}{R T}\left(E-E^{\circ{ }_{\mathrm{E}}}\right)\right\}
\end{aligned}
$$

where $k^{0}, E^{\circ}, n_{E}^{\prime}$, and $\alpha$ are, respectively, the standard rate constant for the electrode reaction, the 
formal redox potential of the enzyme, the number of electrons, and the transfer coefficient.

Here, we consider the steady-state catalytic current caused by the enzymes which are randomly adsorbed $\left(i_{\mathrm{sr}}\right)$ in the range of $0 \leq \theta \leq \theta^{\prime}$. DET-type bioelectrocatalytic current with the enzyme at a certain situation $\left(r_{1}, \theta_{1}, \varphi_{1}\right)$ can be expressed by the product of $i_{s}\left(r_{1}, \theta_{1}, \varphi_{1}\right)$ and $f\left(r_{1}, \theta_{1}\right.$, $\left.\varphi_{1}\right)$. Therefore, $i_{\mathrm{sr}}$ is equal to the integral value of $i_{\mathrm{s}} f$ in the total space, according to Eq. (A.5).

$$
i_{\mathrm{sr}}=\int_{V} i_{\mathrm{s}} f \mathrm{~d} V=\iiint i_{\mathrm{s}} f r \sin \theta \mathrm{d} r \mathrm{~d} \theta \mathrm{d} \phi
$$

In order to solve Eq. (A.5), the dependence of $r, \theta$ and $\varphi$ on $i_{\mathrm{s}}$ is needed. We define $d$ as the increase in the distance between the active site and the electrode in accordance with the change in $\theta$. It is known that the long electron transfer rate constant decreases exponentially on the distance between electron donor and acceptor. The relation between $k^{0}$ and $d$ can be expressed by Eq. (A.6).

$$
k^{\circ}=k_{\text {max }}^{\circ} \exp (-\beta d)
$$

where $k^{0}{ }_{\max }$ is $k^{0}$ at a distance of the closest approach and the $\beta$ is a decay constant. In our model (Fig. A3), $d$ can be expressed with $r_{0}$ and $\theta$ as follows,

$$
d=r_{0}(1-\cos \theta)
$$

Substitution of Eqs. (A.3, A.4, A.6, A.7) for Eq. (A.2) elucidates the dependences of $r, \theta$ and $\varphi$ on $i_{\mathrm{s}}$. Integration in Eq. (A.5) gives the following equation,

$$
\begin{aligned}
& i_{\mathrm{sr}}=\frac{i_{\mathrm{s}}^{\lim }}{\beta r_{0}\left(1-\cos \theta^{\prime}\right)\left[1+\exp \left\{-\frac{n_{\mathrm{E}}^{\prime} F}{R T}\left(E-E^{\mathrm{O}}{ }_{\mathrm{E}}\right)\right\}\right]} \\
& \times \ln \left|\frac{k_{\mathrm{c}} \exp \left\{\frac{\alpha n_{\mathrm{E}}^{\prime} F}{R T}\left(E-E^{\circ{ }_{\mathrm{E}}}\right)\right\}+k^{\circ}{ }_{\max }\left[1+\exp \left\{\frac{n_{\mathrm{E}}^{\prime} F}{R T}\left(E-E^{\circ{ }_{\mathrm{E}}}\right)\right\}\right]}{k_{\mathrm{c}} \exp \left\{\frac{\alpha n_{\mathrm{E}}^{\prime} F}{R T}\left(E-E^{\circ{ }_{\mathrm{E}}}\right)\right\}+k^{\circ}{ }_{\max } \exp \left\{-\beta r_{0}\left(1-\cos \theta^{\prime}\right)\right\}\left[1+\exp \left\{\frac{n_{\mathrm{E}}^{\prime} F}{R T}\left(E-E^{\circ{ }_{\mathrm{E}}}\right)\right\}\right]}\right|
\end{aligned}
$$

Assuming the parameters: $r_{0}=3 \mathrm{~nm}, \theta^{\prime}=\pi, n_{\mathrm{E}}^{\prime}=1, \alpha=0.5, \beta=14 \mathrm{~nm}^{-1}$, and $E_{\mathrm{E}}^{\circ \prime}=$ $-0.3 \mathrm{~V}$, we can consider the dependence of $k^{\circ}{ }_{\text {max }} / k_{\mathrm{c}}$ on the voltammograms (Fig. A4). In addition, we also divided the current contributions from the enzymes in the range of $0 \leq \theta^{\prime} \leq \pi / 4$ 
(as the favorably oriented enzymes) and $\pi / 4 \leq \theta^{\prime} \leq \pi$ (as the unfavorably oriented enzymes) on the voltammograms (broken line and dotted line, respectively, shown in Fig. A5).

\section{Appendix B. Supplementary data}

Supplementary data to this article can be found online at http://dx.doi.org/

\section{Acknowledgements}

This work was supported by Core Research for Evolutional Science and Technology, Japan Science and Technology Agency (to Y. H. and K. K.) and Research Fellowships of Japan Society for the promotion of Science for Young Scientists (to K. S.)

\section{References}

[1] K. A. Vincent, A. Parkin, F. A. Armstrong, Investigating and Exploiting the Electrocatalytic Properties of Hydrogenases, Chem. Rev. 107 (2007) 4366-4413.

[2] H. S. Shafaat, O. Rüdiger, H. Ogata, W. Lubitz, A common active site for hydrogen metabolism under diverse conditions, Biochim. Biophys. Acta 1827 (2013) 986-1002.

[3] T. Yagi, Y. Higuchi, Studies on hydrogenase, Proc. Jpn. Acad., Ser. B 89 (2013) 16-33.

[4] A. Volbeda, L. Martin, P. Liebgott, A. D. Lacey, J. C. Fontecilla-Camps, [NiFe]-hydrogenases revisited: nickel-carboxamido bond formation in a variant with accrued $\mathrm{O}_{2}$-tolerance and a tentative re-interpretation of Ni-SI states, Metallomics 7 (2015) 710-718.

[5] J. Fritsch, P. Scheerer, S. Frielingsdorf, S. Kroschinsky, B. Friedrich, O. Lenz, C. M. T. Spahn, The crystal structure of an oxygen-tolerant hydrogenase uncovers a novel iron-sulphur centre, Nature 479 (2011) 249-252.

[6] T. Goris, A. F. Wait, M. Saggu, J. Fritsch, N. Heidary, M. Stein, I. Zebger, F. Lendzian, F. A. Armstrong, B. Friedrich, O. Lenz, A unique iron-sulfur cluster is crucial for oxygen tolerance of a [NiFe]-hydrogenase, Nat. Chem. Biol. 7 (2011) 310-318. 
[7] M. Pandelia, W. Nitschke, P. Infossi, M. Giudici-Orticoni, E. Bill, W. Lubitz, Characterization of a unique [FeS] cluster in the electron transfer chain of the oxygen tolerant [NiFe] hydrogenase from Aquifex aeolicus, Proc. Natl. Acad. Sci. 108 (2011) 6097-6102.

[8] M. Pandelia, V. Fourmond, P. Tron-Infossi, E. Lojou, P. Bertrand, C. Léger, M. Giudici-Orticoni, W. Lubitz, Membrane-Bound Hydrogenase I from the Hyperthermophilic Bacterium Aquifex aeolicus: Enzyme Activation, Redox Intermediates and Oxygen Tolerance, J. Am. Chem. Soc. 132 (2010) 6991-7004.

[9] M. M. Roessler, R. M. Evans, R. A. Davies, J. Harmer, F. A. Armstrong, EPR Spectroscopic Studies of the Fe-S Clusters in the $\mathrm{O}_{2}$-Tolerant [NiFe]-Hydrogenase Hyd-1 from Escherichia coli and Characterization of the Unique [4Fe-3S] Cluster by HYSCORE, J. Am. Chem. Soc. 134 (2012) 15581-15594.

[10] J. A. Cracknell, A. F. Wait, O. Lenz, B. Friedrich, F. A. Armstrong, A kinetic and thermodynamic understanding of $\mathrm{O}_{2}$ tolerance in [NiFe]-hydrogenases, Proc. Natl. Acad. Sci. 106 (2009) 20681-20686.

[11] Y. Shomura, K. S. Yoon, H. Nishihara, Y. Higuchi, Structural basis for a [4Fe-3S] cluster in the oxygen-tolerant membrane-bound [NiFe]-hydrogenase, Nature 479 (2011) 253-257.

[12] K. S. Yoon, K. Fukuda, K. Fujisawa, H. Nishihara, Purification and characterization of a highly thermostable, oxygen-resistant, respiratory [NiFe]-hydrogenase from a marine, aerobic hydrogen-oxidizing bacterium Hydrogenovibrio marinus, Int. J. Hydrogen Energy 36 (2011) 7081-7088.

[13] J. A. Cracknell, K. A. Vincent, F. A. Armstrong, Enzymes as Working or Inspirational Electrocatalysts for Fuel Cells and Electrolysis, Chem. Rev. 108 (2008) 2439-2461.

[14] M. J. Moehlenbrock, S. D. Minteer, Extended lifetime biofuel cells, Chem. Soc. Rev. 37 (2008) 1188-1196.

[15] N. Mano, F. Mao, A. Heller, A Miniature Membrane-less Biofuel Cell Operating at $+0.60 \mathrm{~V}$ 
under Physiological Conditions, ChemBioChem 5 (2004) 1703-1705.

[16] D. Leech, P. Kavanagha, W. Schuhmann, Enzymatic fuel cells: Recent progress, Electrochim. Acta 84 (2012) 223-234.

[17] S. C. Barton, J. Gallaway, P. Atanassov, Enzymatic Biofuel Cells for Implantable and Microscale Devices, Chem. Rev. 104 (2004) 4867-4886.

[18] C. Léger, P. Bertrand, Direct Electrochemistry of Redox Enzymes as a Tool for Mechanistic Studies, Chem. Rev. 108 (2008) 2379-2438.

[19] M. Rasmussen, S. Abdellaoui, S. D. Minteer, Enzymatic biofuel cells: 30 years of critical advancements, Biosens. Bioelectron. 76 (2016) 91-102.

[20] M. Rasmussen, R. E. Ritzmann, I. Lee, A. J. Pollack, D. Scherson, An Implantable Biofuel Cell for a Live Insect, J. Am. Chem. Soc. 134 (2012) 1458-1460.

[21] A. Szczupak, J. Halámek, L. Halámková, V. Bocharova, L. Alfonta, E. Katz, Living battery - biofuel cells operating in vivo in clams, Energy Environ. Sci. 5 (2012) 8891-8895.

[22] A. Zebda, S. Cosnier, J.-P. Alcaraz, M. Holzinger, A. Le Goff, C. Gondran, F. Boucher, F. Giroud, K. Gorgy, H. Lamraoui, P. Cinquin, Single Glucose Biofuel Cells Implanted in Rats Power Electronic Devices, Sci. Rep. 3 (2013) 1516.

[23] E. Katz, K. MacVittie, Implanted biofuel cells operating in vivo - methods, applications and perspectives - feature article, Energy Environ. Sci. 6 (2013) 2791-2803.

[24] A. D. Poulpiquet, A. Ciaccafava, R. Gadiou, S. Gounel, M. T. Giudici-Orticoni, N. Mano, E. Lojou, Design of a $\mathrm{H}_{2} / \mathrm{O}_{2}$ biofuel cell based on thermostable enzymes, Electrochem. Commun. 42 (2014) 72-74.

[25] L. Xu, F. A. Armstrong, Optimizing the power of enzyme-based membrane-less hydrogen fuel cells for hydrogen-rich $\mathrm{H}_{2}$-air mixtures, Energy Environ. Sci. 6 (2013) 2166-2171.

[26] A. D. Poulpiquet, D. Ranava, K. Monsalve, M. T. Giudici-Orticoni, E. Lojou, Biohydrogen for a New Generation of $\mathrm{H}_{2} / \mathrm{O}_{2}$ Biofuel Cells: A Sustainable Energy Perspective, 
ChemElectroChem 1 (2014) 1724-1750.

[27] N. Lalaoui, A. D. Poulpiquet, R. Haddad, A. L. Goff, M. Holzinger, S. Gounel, M. Mermoux, P. Infossi, N. Mano, E. Lojou, S. Cosnier, A membraneless air-breathing hydrogen biofuel cell based on direct wiring of thermostable enzymes on carbon nanotube electrodes, Chem. Commun. 51 (2015) 7447-7450.

[28] E. I. Solomon, U. M. Sundaram, T. E. Machonkin, Multicopper Oxidases and Oxygenases, Chem. Rev. 96 (1996) 2563-2606.

[29] K. So, S. Kawai, Y. Hamano, Y. Kitazumi, O. Shirai, M. Hibi, J. Ogawa, K. Kano, Improvement of a direct electron transfer-type fructose/dioxygen biofuel cell with a substrate-modified biocathode, Phys. Chem. Chem. Phys. 16 (2014) 4823-4829.

[30] N. Mano, L. Edembe, Bilirubin oxidases in bioelectrochemistry: Features and recent findings, Biosens. Bioelectron. 50 (2013) 478-485.

[31] S. Kawai, M. Tsutsumi, T. Yakushi, K. Kano, K. Matsushita, Heterologous Overexpression and Characterization of a Flavoprotein-cytochrome c Complex Fructose Dehydrogenase of Gluconobacter japonicus NBRC3260, Appl. Environ. Microbiol. 79 (2013) 1654-1660.

[32] S. Kawai, T. Yakushi, K. Matsushita, Y. Kitazumi, O. Shirai, K. Kano, The electron transfer pathway in direct electrochemical communication of fructose dehydrogenase with electrodes, Electrochem. Commun. 38 (2014) 28-31.

[33] A. Lindgren, L. Gorton, T. Ruzgas, U. Baminger, D. Haltrich, M. Schülein, Direct electron transfer of cellobiose dehydrogenase from various biological origins at gold and graphite electrodes, J. Electroanal. Chem. 496 (2001) 76-81.

[34] V. Fridman, U. Wollenberger, V. Bogdanovskaya, F. Lisdat, T. Ruzgas, A. Lindgren, L. Gorton, F. W. Scheller, Electrochemical investigation of cellobiose oxidation by cellobiose dehydrogenase in the presence of cytochrome c as mediator, Biochem. Soc. Trans. 28 (2000) 63-70.

[35] C. Léger, A. K. Jones, S. P. J. Albracht, F. A. Armstrong, Effect of a Dispersion of 
Interfacial Electron Transfer Rates on Steady State Catalytic Electron Transport in [NiFe]-hydrogenase and Other Enzymes, J. Phys. Chem. B 106 (2002) 13058-13063.

[36] C. C. Page, C. Moser, X. Chen, P. L. Dutton, Natural engineering principles of electron tunnelling in biological oxidation-reduction, Nature 402 (1999) 47-52.

[37] C. Léger, A. K. Jones, W. Roseboom, S. P. J. Albracht, F. A. Armstrong, Enzyme Electrokinetics: Hydrogen Evolution and Oxidation by Allochromatium vinosum [NiFe]-Hydrogenase, Biochemistry 41 (2002) 15736-15746.

[38] V. Fourmond, C. Baffert, K. Sybirna, T. Lautier, A. A. Hamdan, S. Dementin, P. Soucaille, I. Meynial-Salles, H. Bottin, C. Léger, Steady-State Catalytic Wave-Shapes for 2-Electron Reversible Electrocatalysts and Enzymes, J. Am. Chem. Soc. 135 (2013) 3926-3938.

[39] A. A. Hamdan, B. Burlat, O. Gutiérrez-Sanz, P. Liebgott, C. Baffert, A. L. D. Lacey, M. Rousset, B. Guigliarelli, C. Léger, S. Dementin, $\mathrm{O}_{2}$-independent formation of the inactive states of NiFe hydrogenase, Nat. Chem. Biol. 9 (2013) 15-17.

[40] A. A. Hamdan, P. Liebgott, V. Fourmond, O. Gutiérrez-Sanz, A. D. Lacey, P. Infossi, M. Rousset, S. Dementin, C. Léger, Relation between anaerobic inactivation and oxygen tolerance in a large series of NiFe hydrogenase mutants, Proc. Natl. Acad. Sci. 109 (2012) 19916-19921.

[41] K. So, Y. Kitazumi, O. Shirai, K. Kurita, H. Nishihara, Y. Higuchi, K. Kano, Kinetic Analysis of Inactivation and Enzyme Reaction of Oxygen-Tolerant [NiFe]-Hydrogenase at Direct Electron-Transfer Bioanode, Bull. Chem. Soc. Jpn. 87 (2014) 1177-1185.

[42] V. Fourmond, P. Infossi, M. Giudici-Orticoni, P. Bertrand, C. Léger, “Two-Step” Chronoamperometric Method for Studying the Anaerobic Inactivation of an Oxygen Tolerant NiFe Hydrogenase, J. Am. Chem. Soc. 132 (2010) 4848-4857.

[43] N. Plumeré, O. Rüdiger, A. A. Oughli, R. Williams, J. Vivekananthan, S. Pöller, W. Schuhmann, W. Lubitz, A redox hydrogel protects hydrogenase from high-potential deactivation and oxygen damage, Nat. Chem. 6 (2014) 822-827. 
[44] K. So, Y. Kitazumi, O. Shirai, K. Kurita, H. Nishihara, Y. Higuchi, K. Kano, Gas-diffusion and Direct-electron-transfer-type Bioanode for Hydrogen Oxidation with Oxygen-tolerant [NiFe]-hydrogenase as an Electrocatalyst, Chem. Lett. 43 (2014) 1575-1577.

[45] C. L. Young, Ed. Hydrogen and Deuterium. IUPAC Solubility Data Series, Vol. 5/6, Pergamon Press Oxford, England, 1981.

[46] A. K. Jones, S. E. Lamle, H. R. Pershad, K. A. Vincent, S. P. J. Albracht, F. A. Armstrong, Enzyme Electrokinetics: Electrochemical Studies of the Anaerobic Interconversions between Active and Inactive States of Allochromatium vinosum [NiFe]-hydrogenase, J. Am. Chem. Soc. 125 (2003) 8505-8514.

[47] D. Sehgal, I. K. Vijay, A method for the high efficiency of water-soluble carbodiimide-mediated amidation, Anal. Biochem. 218 (1994) 87-91.

[48] B. L. Greene, C. Wu, P. M. McTernan, M. W. W. Adams, R. B Dyer, Proton-Coupled Electron Transfer Dynamics in the Catalytic Mechanism of a [NiFe]-Hydrogenase, J. Am. Chem. Soc. 137 (2015) 4558-4566.

[49] A. L. D. Lacey, E. C. Hatchikian, A. Volbeda, M. Frey, J. C. Fontecilla-Camps, V. M. Fernandez, Infrared-Spectroelectrochemical Characterization of the [NiFe] Hydrogenase of Desulfovibrio gigas, J. Am. Chem. Soc. 119 (1997) 7181-7189.

[50] T. Ikeda, D. Kobayashi, F. Matsushita, T. Sagara, K. Niki, Bioelectrocatalysis at electrodes coated with alcohol dehydrogenase, a quinohemoprotein with heme c serving as a built-in mediator, J. Electroanal. Chem. 361 (1991) 221-228.

[51] S. Tsujimura, T. Nakagawa, K. Kano, T. Ikeda, Kinetic study of direct bioelectrocatalysis of dioxygen reduction with bilirubin oxidase at carbon electrodes, Electrochemistry 72 (2004) 437-439. 
Figure captions

\section{Scheme 1.}

The reaction scheme of the $\mathrm{H}_{2}$ oxidation catalytic cycle, the irreversible inactivation and the reversible inactivation (oxidative inactivation). Ni-SI, $\mathrm{Ni}-\mathrm{R}, \mathrm{Ni}-\mathrm{C}, \mathrm{Ni}-\mathrm{A}$, and $\mathrm{Ni}-\mathrm{B}$ are, respectively, the active silent state of [ $\mathrm{NiFe}$-hydrogenases, $\mathrm{H}_{2}$-reduced state of the $\mathrm{Ni}$-SI state, one electron-oxidized state of the Ni-R state, the state caused by the irreversible inactivation, and the state caused by the oxidative inactivation.

\section{Scheme 2.}

The reaction scheme of the $\mathrm{H}_{2}$ oxidation catalytic cycle for Nernst analysis. $K_{\mathrm{M}}, k_{\text {cat }}, E_{\mathrm{Ni}-\mathrm{C} / \mathrm{Ni}-\mathrm{SI}}$, and $E^{\mathrm{O}}{ }_{\mathrm{Ni}-\mathrm{R} / \mathrm{Ni}-\mathrm{C}}$ are, respectively, the Michaelis constant for $\mathrm{H}_{2}$, the catalytic constant, the formal redox potentials of $\mathrm{Ni}-\mathrm{C} / \mathrm{Ni}-\mathrm{SI}$ and $\mathrm{Ni}-\mathrm{R} / \mathrm{Ni}-\mathrm{C}$ redox couples.

\section{Scheme 3.}

The reaction scheme of the catalytic $\mathrm{H}_{2}$ oxidation for digital simulation. $k_{1}, k_{-1}, k_{2}, k_{-2}, k_{3}, k_{-3}$, $k_{4}, k_{-4}$ and $k_{\text {cat }}$ are, respectively, the forward and backward rate constants of the $\mathrm{H}_{2}$-binding, the true rate constants of inactivation and reactivation, the electrode reaction rate constants of $\mathrm{Ni}-\mathrm{C} / \mathrm{Ni}-\mathrm{SI}$ and $\mathrm{Ni}-\mathrm{R} / \mathrm{Ni}-\mathrm{C}$ redox couples and the catalytic constant.

\section{Figure 1.}

CVs of the $\mathrm{HmMBH}$-adsorbed Au electrode in $\mathrm{H}_{2}$-(solid line) and Ar-saturated (broken line) buffer solution under quiescent conditions. The scan rates of solid lines were $5-100 \mathrm{mV} \mathrm{s}^{-1}$ from bottom to top (grey to black). The scan rate of a broken line was $10 \mathrm{mV} \mathrm{s}^{-1}$. The measurements were carried out in McIlvaine buffer (pH 5.5) at $25 \pm 2{ }^{\circ} \mathrm{C}$.

\section{Figure 2.}

Nernst analysis on the $\mathrm{HmMBH}$-catalyzed $\mathrm{H}_{2}$ oxidation current. Background-pre-subtracted and normalized voltammograms (forward scan of CV in Figure 1, $\mathrm{V}=5 \mathrm{mV} \mathrm{s}^{-1}$ ) were shown in open 
circles. The solid curve was evaluated by a non-linear regression analysis based on Eq. (7).

\section{Figure 3.}

Pourbaix diagrams of Ni-C/Ni-SI (open circles) and Ni-R/Ni-C (open triangles) redox couples. The solid line was generated by linearization of the regression curve based on Eq. (8) with slopes of 2.303(RT/F)(m/n) ( $m=0$ or $1, n=1$ in this case) by considering the acid dissociations of the Ni-SI and Ni-C states. The dotted line was generated by linearization of the regression curve based on Eq. (9) with slopes of the theoretical values of $2.303(R T / F)(m / n)(m=0$ or $1, n=1$ in this case) by considering the acid dissociations of the $\mathrm{Ni}-\mathrm{C}$ and $\mathrm{Ni}-\mathrm{R}$ states. The error bars are given as the asymptotic standard error obtained by the non-linear regression analysis of the voltammograms (see Fig. 2). The closed triangles indicate the half-wave potential in the sigmoidal response (see Fig. 2)

\section{Figure 4.}

CA of the chemically immobilized $H m M B H$-adsorbed $\mathrm{Au}$ electrode at $-0.02 \mathrm{~V}$ under $\mathrm{H}_{2}$-atmospheric conditions. The measurements were carried out in $100 \mathrm{mM}$ phosphate buffer (pH 6) at $40 \pm 2{ }^{\circ} \mathrm{C}$. The solid curve was evaluated by a non-linear regression analysis based on Eq. (10). The best fit was obtained with the parameters: $i_{0}=0.35 \mu \mathrm{A}, k_{\mathrm{I}}=0.11 \mathrm{~s}^{-1}$ and $k_{\mathrm{A}}=0.057 \mathrm{~s}^{-1}$.

\section{Figure 5.}

The potential dependence of the apparent rate constants of the inactivation (panel A) and the reactivation (panel B). The open circles and triangles correspond to the results obtained at $\mathrm{HmMBH}$-adsorbed Au electrode and chemically immobilized $\mathrm{HmMBH}$-adsorbed Au electrode, respectively. The data for the $\mathrm{HmMBH}$-adsorbed Au electrode are almost identical with those in Fig. 4 in Ref. 41 . The error bars were evaluated by the Student $t$-distribution at $90 \%$ confidence level.

\section{Figure 6.}

Simulated $\mathrm{CVs}$ of the $\mathrm{HmMBH}$-adsorbed electrode under $\mathrm{H}_{2}$-saturated conditions. The scan rates were $5-100 \mathrm{mV} \mathrm{s}^{-1}$ from bottom to top (grey to black). The parameters were estimated from the results measured at $\mathrm{pH} 6$. 


\section{Figure 7.}

Effects of the $\mathrm{H}_{2}$-concentration on simulated $\mathrm{CVs}$ of the $\mathrm{HmMBH}$-adsorbed electrode. The scan rate is $10 \mathrm{mV} \mathrm{s}^{-1}$. The $\mathrm{H}_{2}$-concentrations are $0.37,0.74,1.48,2.96,5.92,11.8,23.7$, and $47.4 \mathrm{mM}$ from bottom to top (grey to black). The important parameters used are those estimated in this work. 


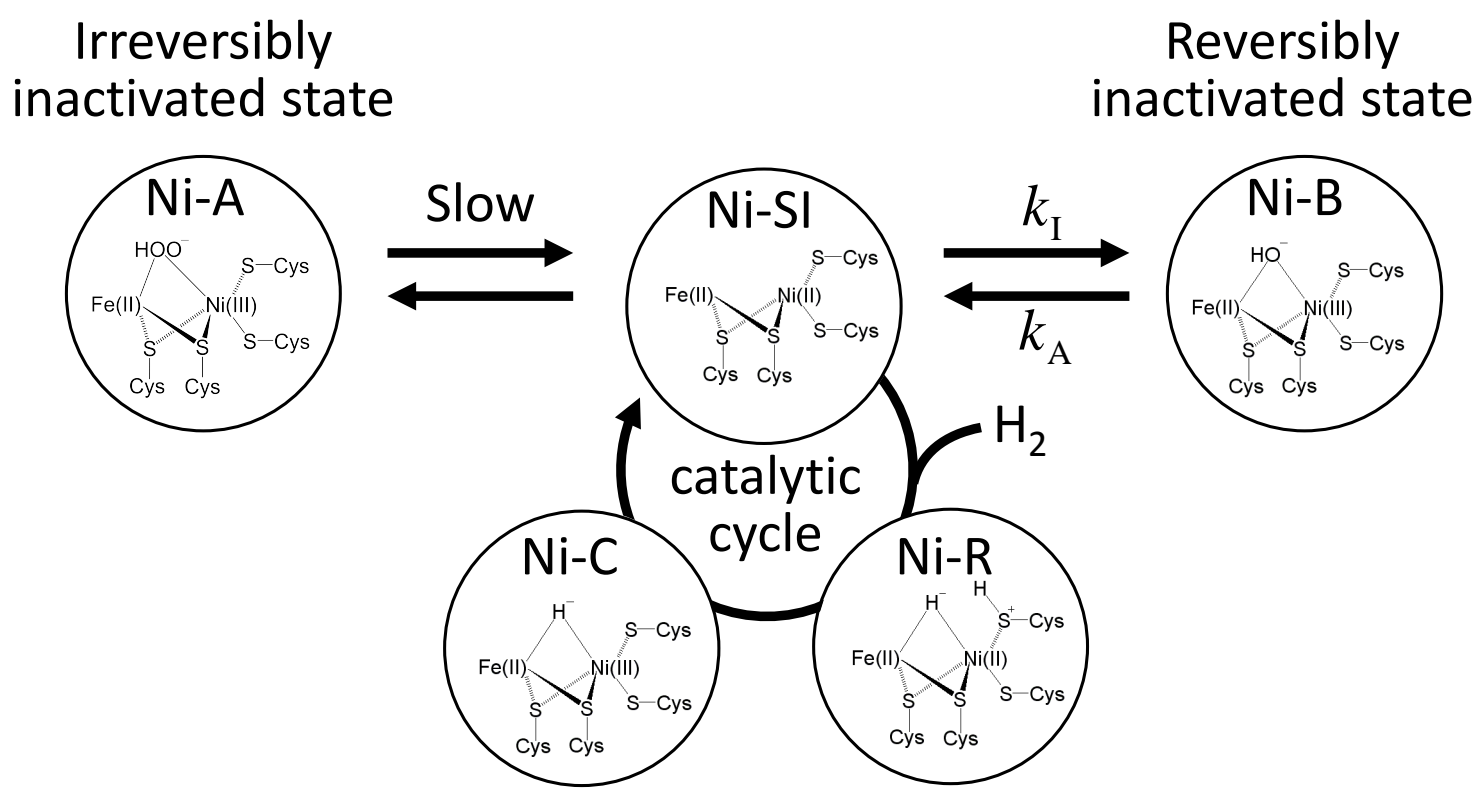

Scheme $1 \quad K$. So et al. 


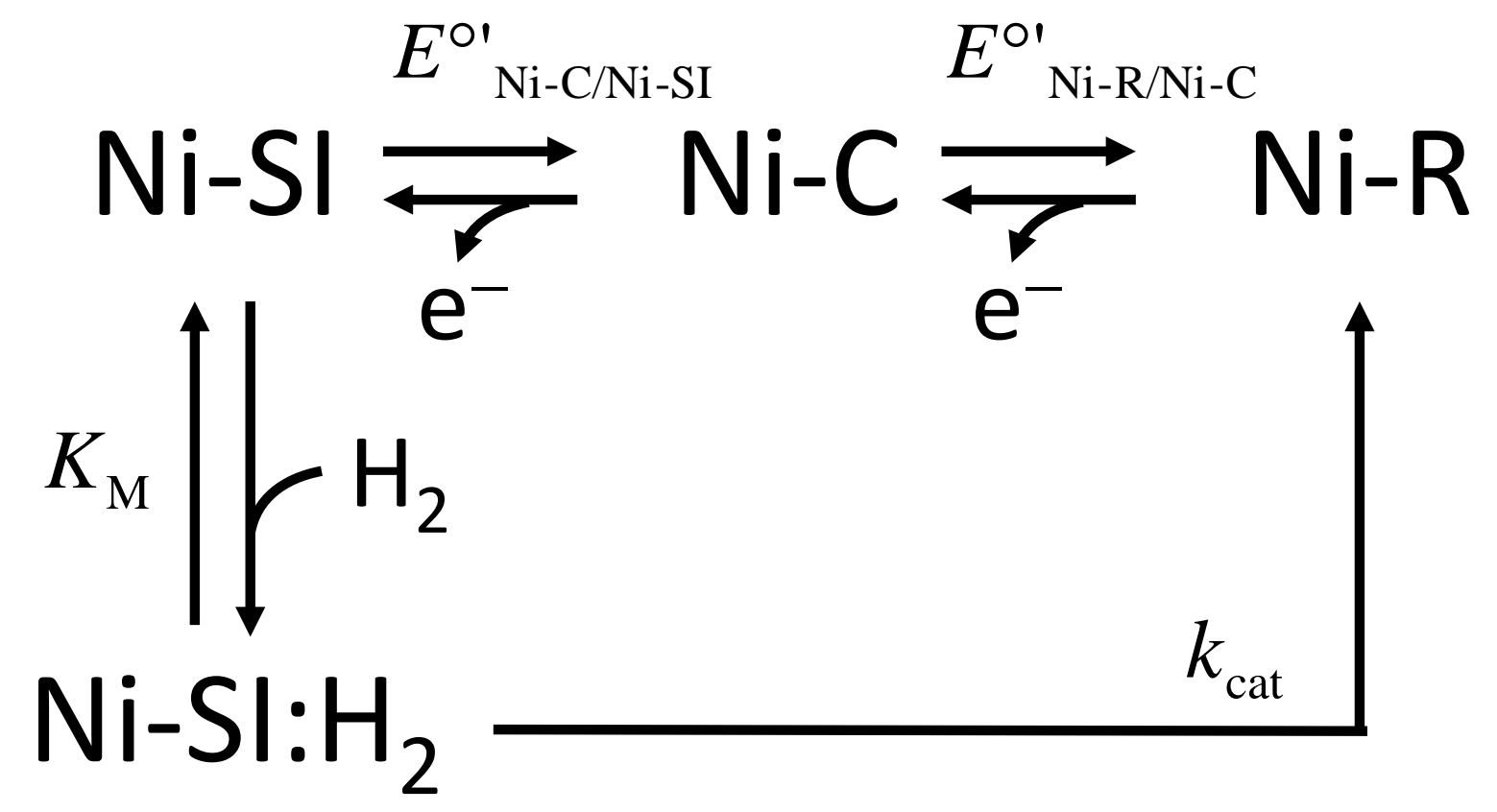

Scheme 2 K. So et al. 


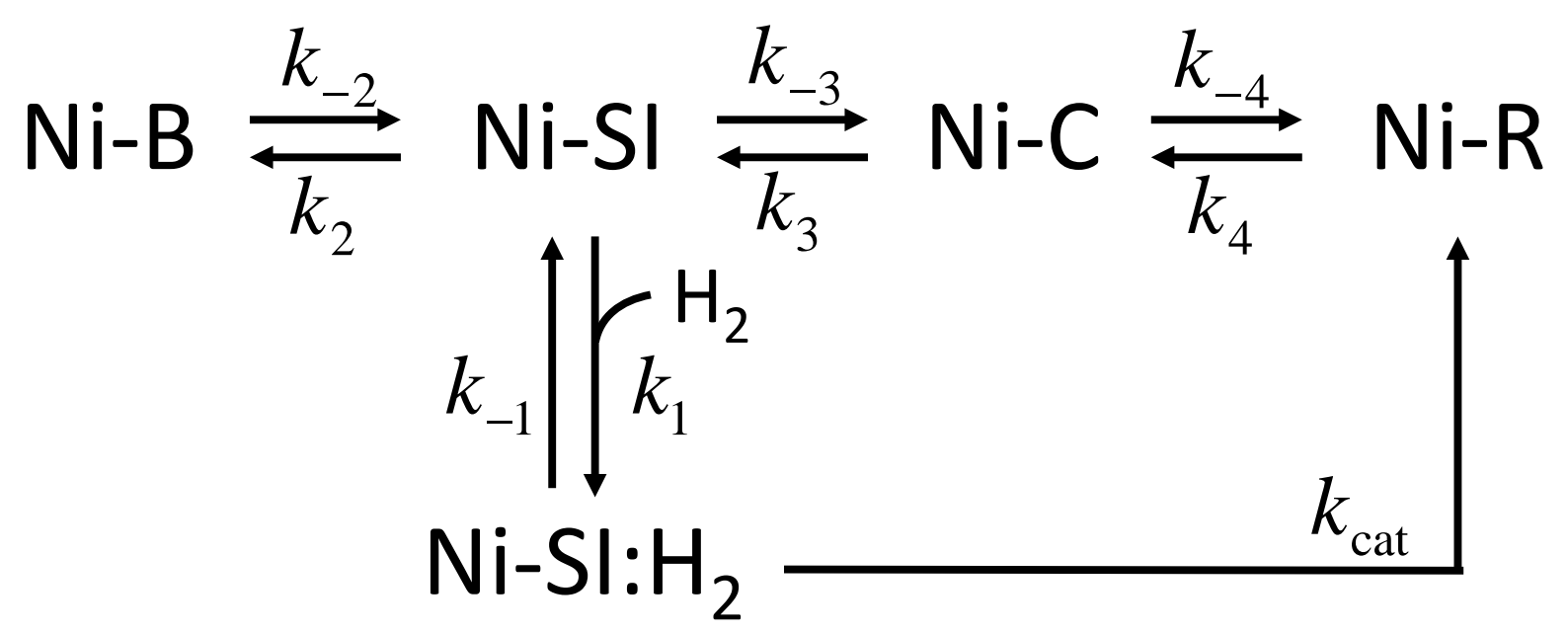

Scheme 3 K. So et al. 


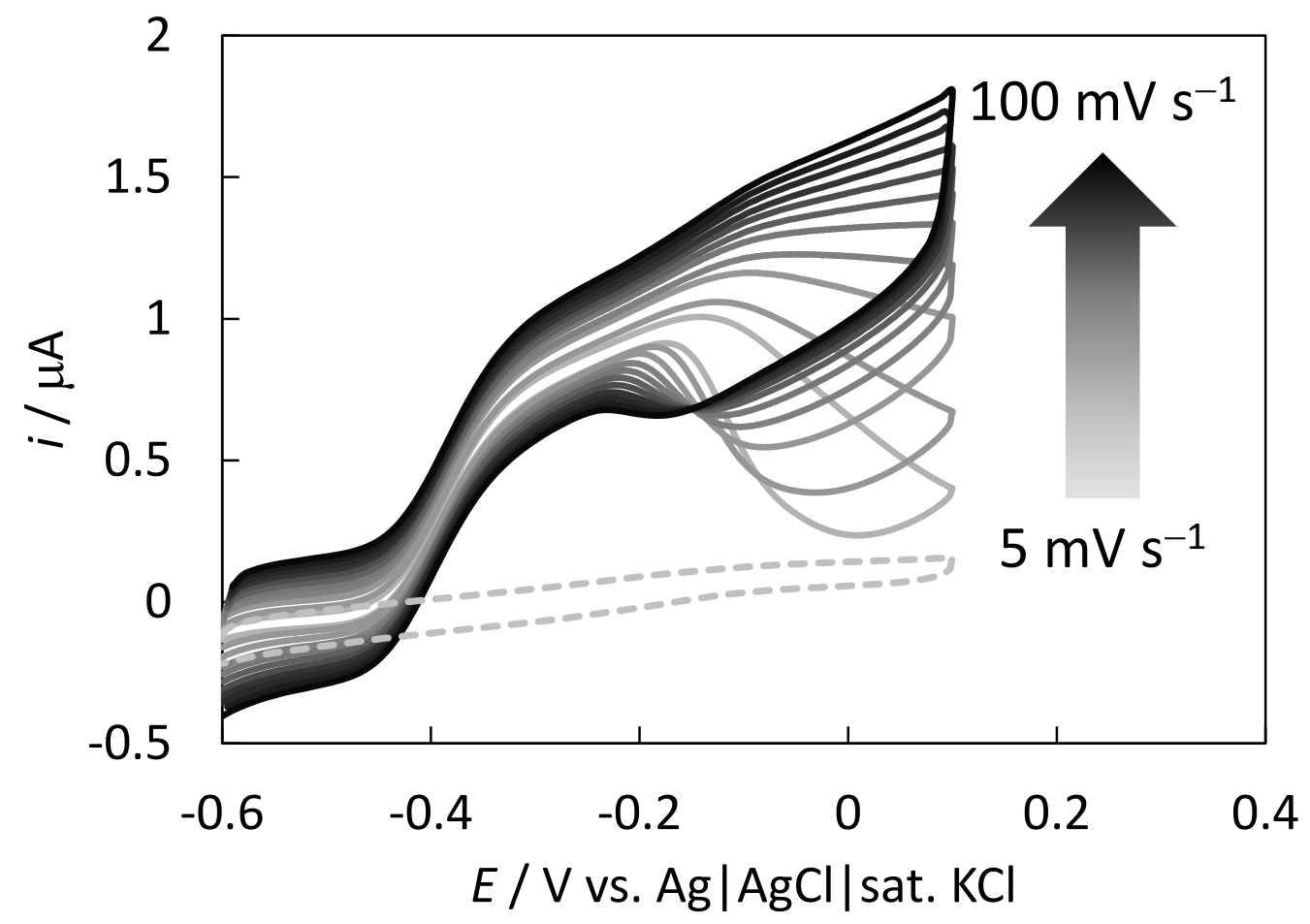

Fig. $1 \quad$ K. So et al. 


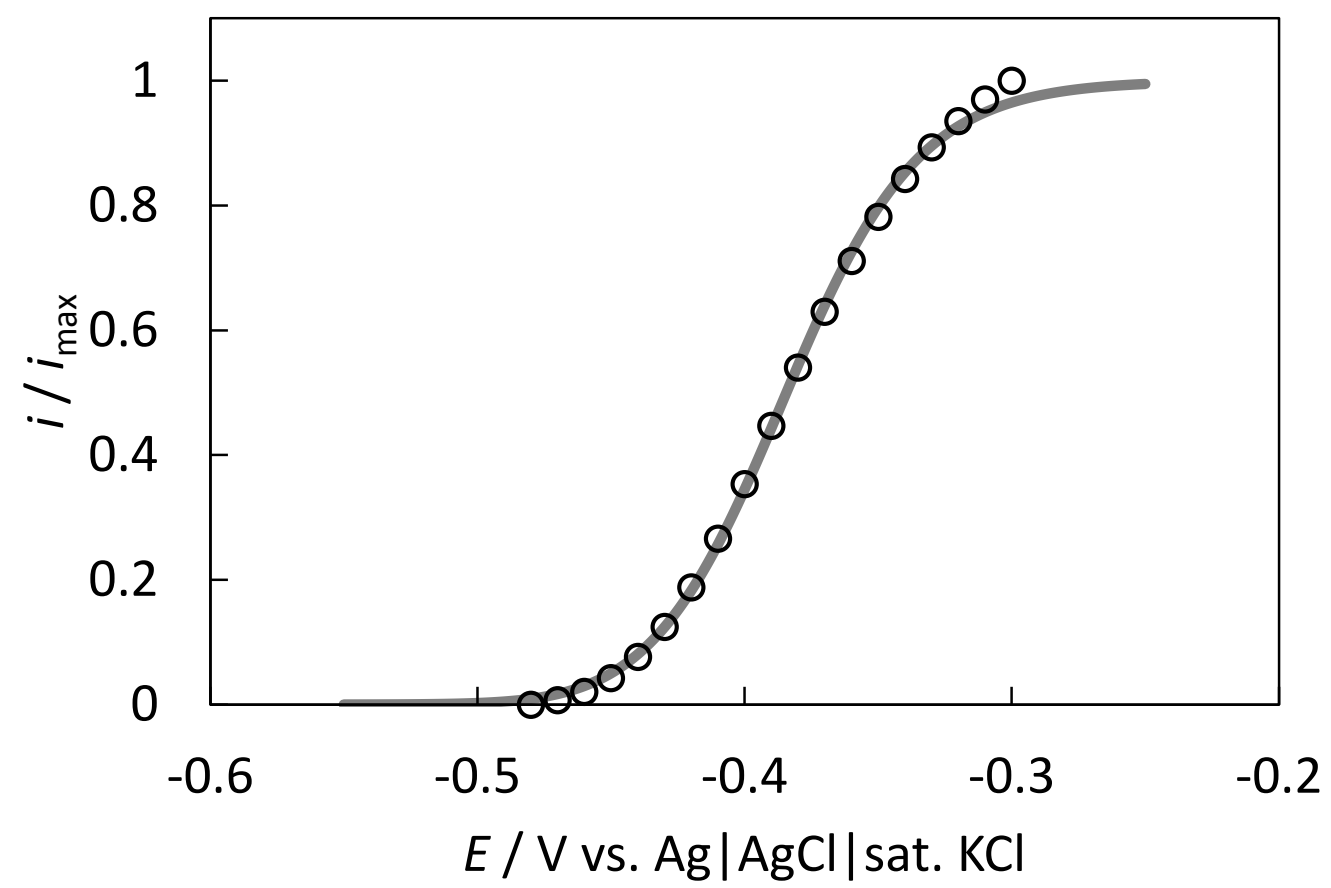

Fig. 2 K. So et al. 


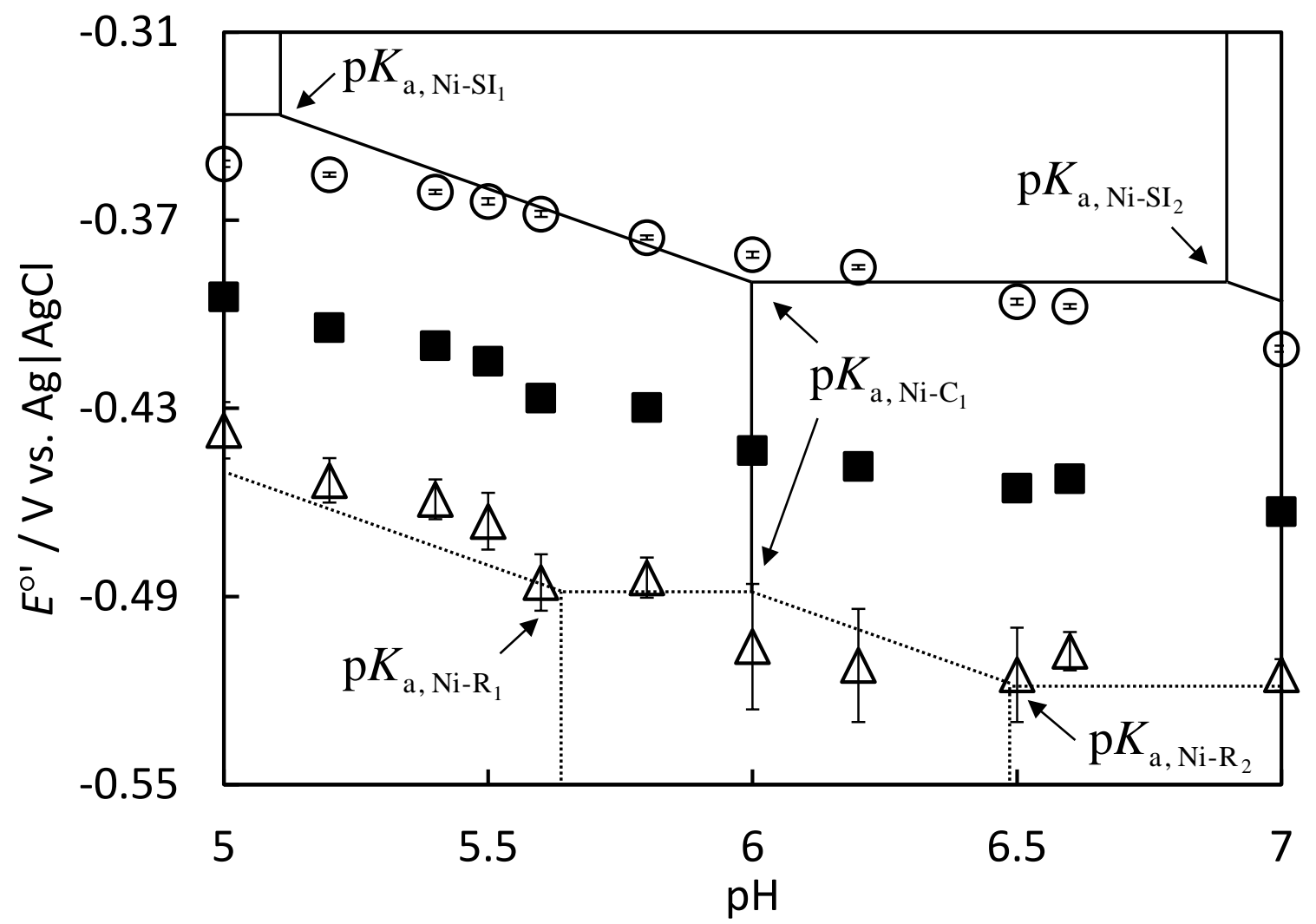

Fig. $3 \quad$ K. So et al. 


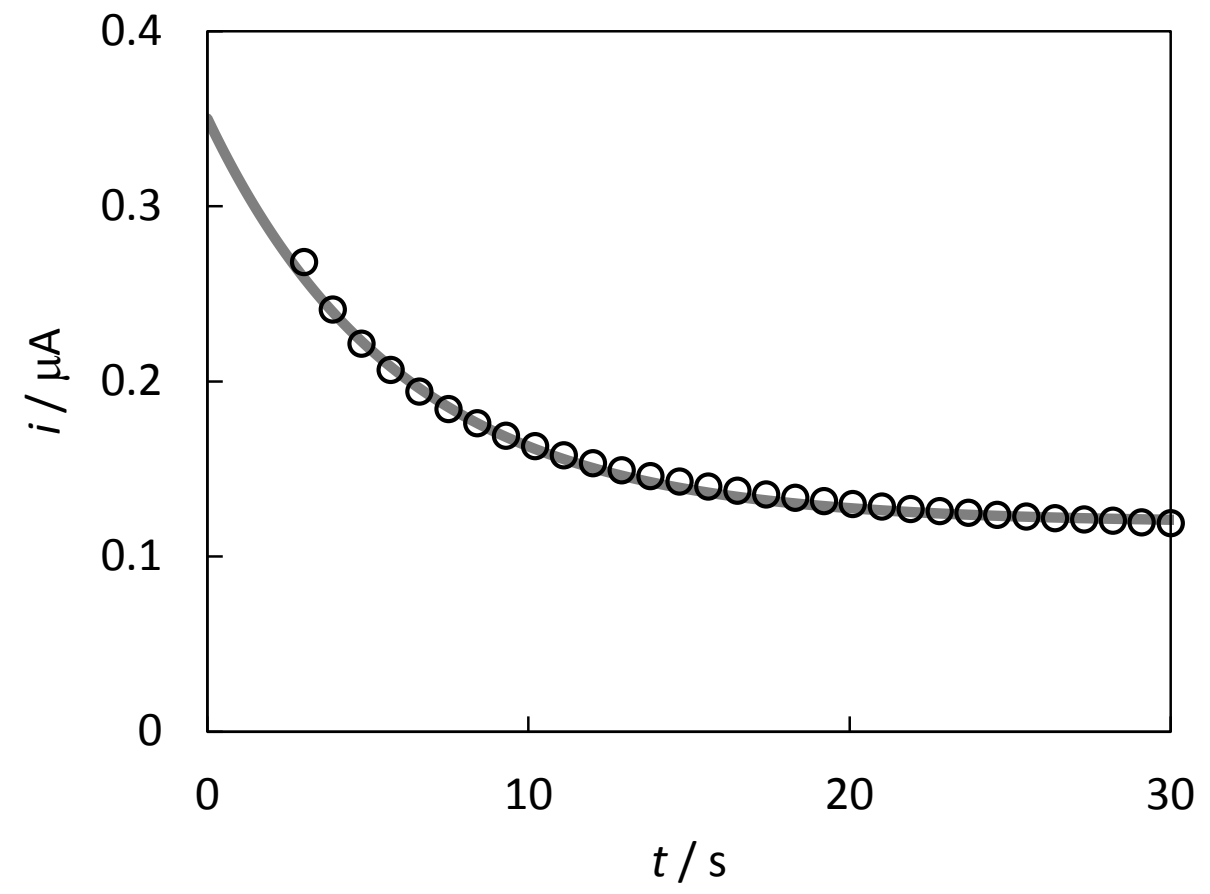

Fig. 4 K. So et al. 

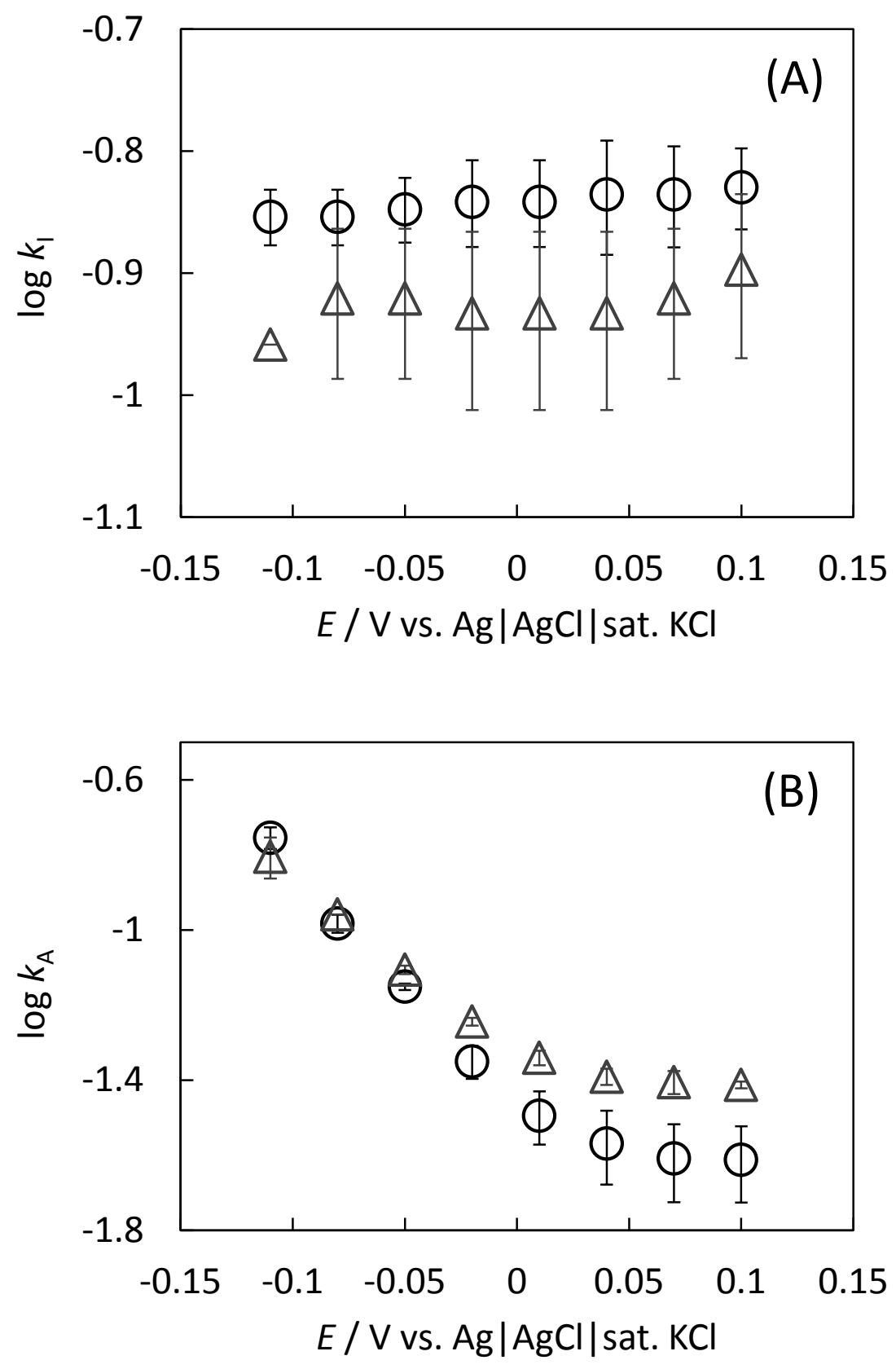

Fig. $5 \quad$ K. So et al. 


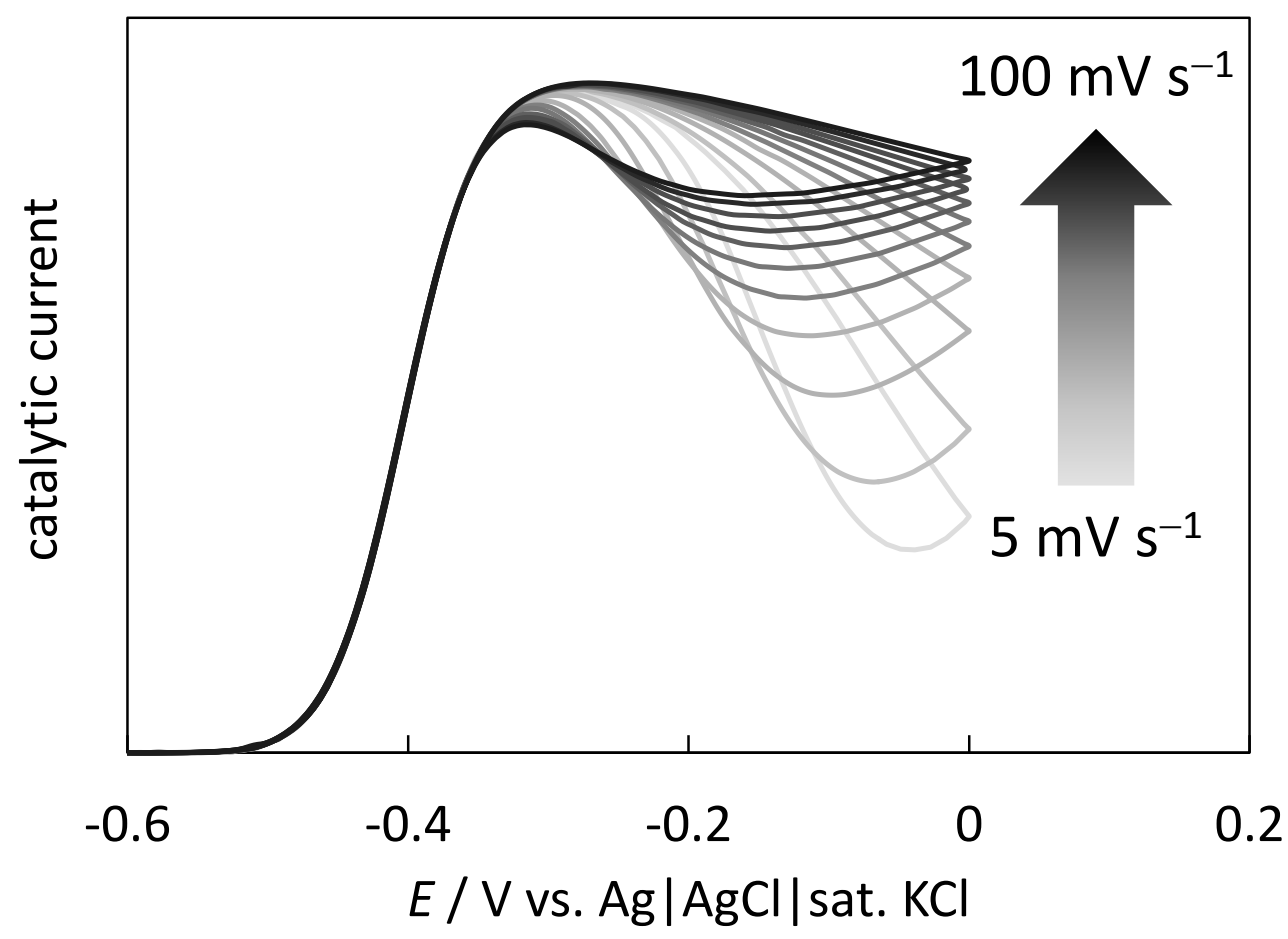

Fig. $6 \quad$ K. So et al. 


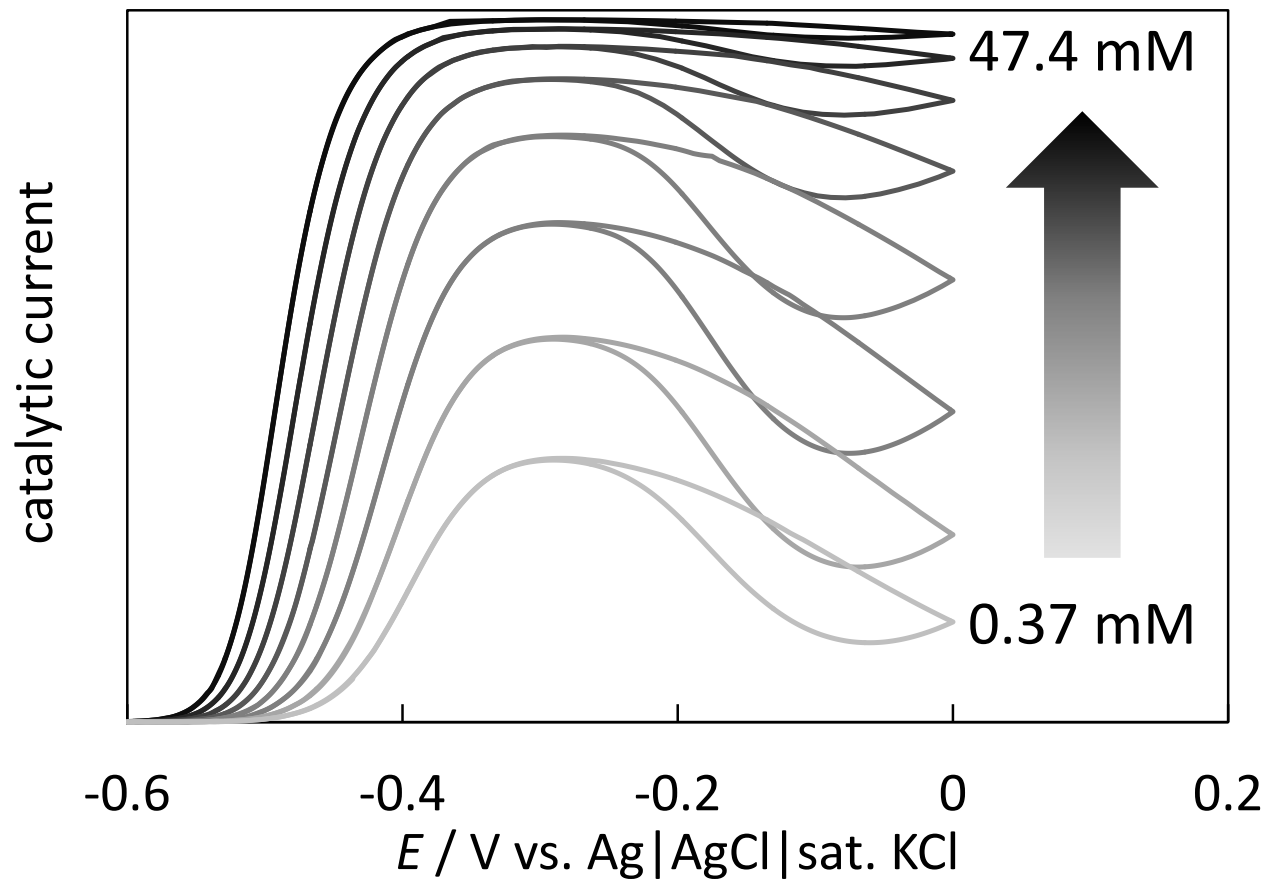

Fig. $7 \quad$ K. So et al. 
Bioelectrochemical analysis of thermodynamics of the catalytic cycle and kinetics of the oxidative inactivation of oxygen-tolerant [NiFe]-hydrogenase

Keisei So a, Rui Hamamoto a, Yuki Kitazumi ${ }^{a}$, Osamu Shirai ${ }^{\text {a, b }}$, Ryohei Endo c, Hirofumi Nishihara ${ }^{\mathrm{c}}$, Yoshiki Higuchi ${ }^{\text {b, d }}$, and Kenji Kano ${ }^{\text {a, b * }}$

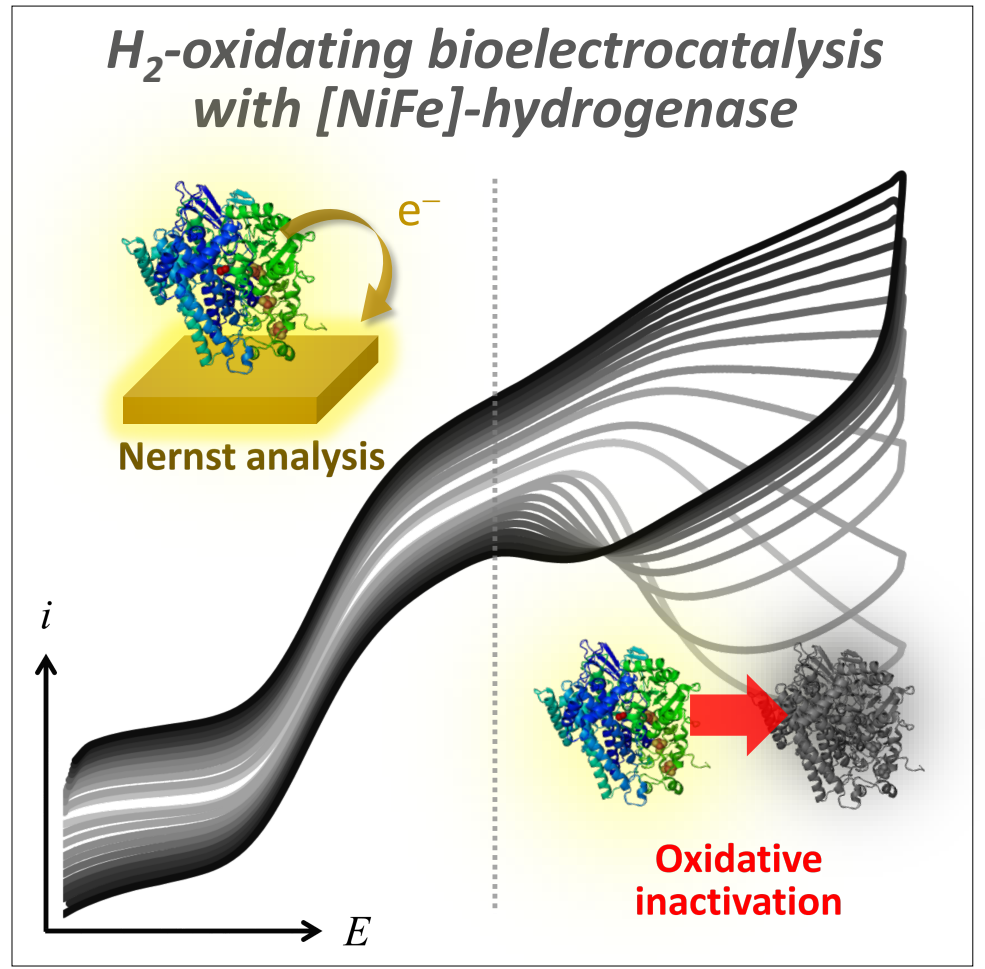

